Jin, R., Zou, P.X.W., Piroozfar, P., Hannah, W., Yang, Y., Yan, L., and Han, Y. (2019). “A Science Mapping Approach Based Review of Construction Safety Research” Safety Science, in Press. Accepted on 5 December 2018.

\title{
A Science Mapping Approach Based Review of Construction Safety Research
}

- The study applied science mapping approach in reviewing construction safety research.

- Mainstream keywords such as BIM were identified in existing literature.

- Influential journals, scholars, and articles in construction safety were evaluated.

- An in-depth qualitative discussion identified existing research topics and limitations.

- A research framework was proposed by linking mainstream topics into future research directions.

\section{Abstract}

This study adopted a three-step holistic review approach consisting of bibliometric review, scientometric analysis, and in-depth discussion to gain a deeper understanding of the research development in construction safety. Focusing on a total of 513 journal articles published in Scopus, the influential journals, keywords, scholars, and articles in the domain of construction safety were analyzed. For example, simulation and fall from height related topics, although not with the highest occurrence of being studied, had the highest impact in terms of average citation received per year. It was found that research in the recent 10 years have been extended to the developing countries and regions with a more variety of research topics, such as BIM, and data mining, etc. Articles related to applying BIM in safety management received the highest average normalized citation. A follow-up qualitative discussion targeted three main objectives: summarizing mainstream research topics, identifying existing research gaps, and proposing future research directions. Five main categories were aligned, namely safety climate and safety culture, application of information technologies, worker-oriented safety, safety management program, and hazard recognition and risk assessment. Based on the above, a framework and future research directions were proposed which could serve both the academic community and practical fields in multiple themes within construction safety, including: an adaptable safety 
31 climate and safety culture model; prototypes, continuous development, and readiness of applying information technologies in safety management; subgroups factors linked to cognitive models of workers' safety perceptions and behaviors; and artificial intelligence and smart technologies into safety program management.

Keywords: construction safety; human factor; scientometric review; science mapping; literature review

\section{Introduction}

Construction is regarded as one of the most unsafe industries worldwide (Lingard and Rowlinson, 2015). For example, the incident rates, which represent the number of injuries and illnesses in the construction industry, were significantly higher than the national average among all industries in the U.S. (U.S. Bureau of Labor Statistics, 2016). Similar challenges exist in other countries (Fang et al., 2016). Research in improving the safety performance of the construction industry has been continuing in the past decades, covering multiple areas such as safety performance measurement (Liu et al., 2018), safety program (Chen and Jin, 2013), and human factors (Liao et al., 2018). In recent years, due to the growing application of digital technology such as BIM (i.e., Building Information Modeling) in construction, researchers have started applying BIM in enhancing safety planning and site monitoring (Cheung et al., 2018; Choe et al., 2014). Adopting the literature review is an expedient approach to gain an indepth understanding of a research domain (He et al., 2017). So far there has been limited studies adopting a holistic review of human factor-oriented construction safety literature that covers these aforementioned issues (e.g., safety program, BIM, and human factors, etc.) Martínez-Aires et al. (2018), and Mohammadi et al. (2018) are based on the manual reviews, which could be prone to subjectivity or even biasedness as indicated by Hosseini et al. (2018). 
56 the field of construction engineering and management to address the subjectivity issue, these

57 existing scientometric review-based studies were limited to self-exploratory topics such as the most productive scholar, the most influential journal, and most frequently searched keywords

59 (Jin et al., 2018). The level of details presented in these previous reviews could be enhanced 60 (Jin et al., 2018). This review-based study applied the science mapping approach by reviewing 61 journal articles published in the domain of construction safety. The objectives of this study 62 include: 1) applying science mapping approach to analyze the influential journals, keywords, 63 scholars, and articles in the domain of construction safety; 2) analyzing the existing mainstream 64 research topics in construction safety; 3) discussing the limitations or gaps of existing research 65 in the construction safety domain; and 4) proposing the research framework guiding future 66 scholarly and research work. This review-based study introduces the science mapping approach 67 into the domain of construction safety, and provides recommendations for future-research in 68 sub-themes within construction safety.

\section{2. Methodology}

70 This study adopted a three-step literature review approach summarizing the research domain 71 of construction safety. The science mapping approach which consisted of bibliometric analysis 72 and scientometric analysis, was adopted in the review. The detailed workflow of the review is 73 illustrated in Figure 1. 

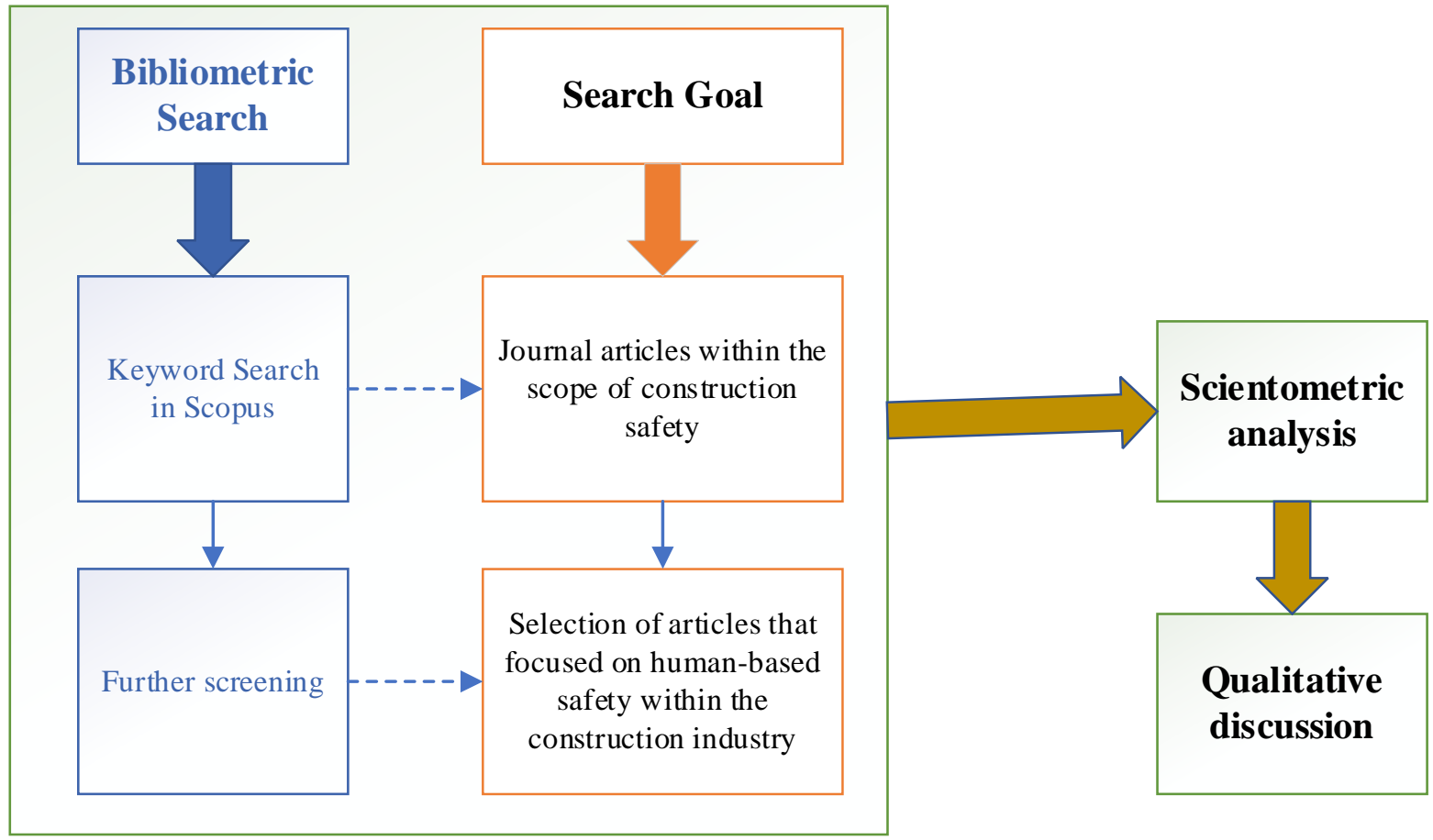

Fig. 1: Description of the three-step literature review process

\subsection{Bibliometric search}

The first step of the review was the bibliometric search in Scopus. The keyword “construction safety” was input to search literature published in Scopus. Scopus covered more journals and more recent publications compared to any other available digital sources (e.g., Web of Science) (Aghaei Chadegani et al., 2013). Initially, 1,738 documents were found. These documents were further screened by including only journal articles published in English. Conference papers were excluded from the sample because they have been released in a large quantity but with less valuable or useful information compared to journal articles (Butler and Visser, 2006). After this initial screening, totally 633 articles remained in the literature sample. According to Fig.1, further refinements of the remaining 633 articles were studied of their titles, abstract, and keywords in details. Some articles, such as Zhang et al. (2018b), although with the term "construction safety" in its abstract, did not focus on safety in construction. Similar articles that did not focus on safety issues in the construction industry were removed. Another type of articles (e.g., Song et al., 2018), although within the context of construction industry, focused on risk assessment which was wider than the scope of safety risks. Similar articles 
91 were also excluded. Further, it should be noticed that the the scope of this review-based study

92 is human-centered safety management, it covered the safety planning and site management,

93 but excluded other safety issues that do not direct focus on construction employees’ safety, for

94 example, structural or material safety for buildings (Peng, 2017). After the final round of

95 screening, ultimately a total of 513 journal articles were selected as the literature sample for

96 the follow-up scientometric analysis.

\subsection{Scientometric analysis}

The second step of the review involved a scientometric analysis method by utilizing the text-mining tool VOSViewer (van Eck and Waltman, 2010). More background information of scientometric analysis can be found in Hosseini et al. (2018). VOSViewer creates distancebased visualizations of networks where the distances among nodes show the level of closeness among them (Van Eck and Waltman, 2014). It is suitable for visualizing larger networks with special text mining features (Van Eck and Waltman, 2014). Using VOSViewer, literature sample obtained from the bibliometric search was transported into VOSViewer for scientometric analysis, which further generated results related to the influences of journals, keywords, scholars, and articles in the domain of construction safety.

\subsection{Qualitative discussion}

Based on the keyword analysis as well as articles analyzed in the prior step, the follow-up qualitative discussion aims to provide an in-depth evaluation of the three main research objectives related to the mainstream research topics in the domain of construction safety, the

112 current research gaps or limitations, as well as the future recommended research work. Finally

113 a framework linking the existing research topics to future directions is proposed for scholars

114 within the academic community of construction safety to continue the research work of construction safety. 


\section{Results}

118 The 513 journal articles were firstly summarized according to their publication year. Figure

1192 display the articles’ distribution of publication years.

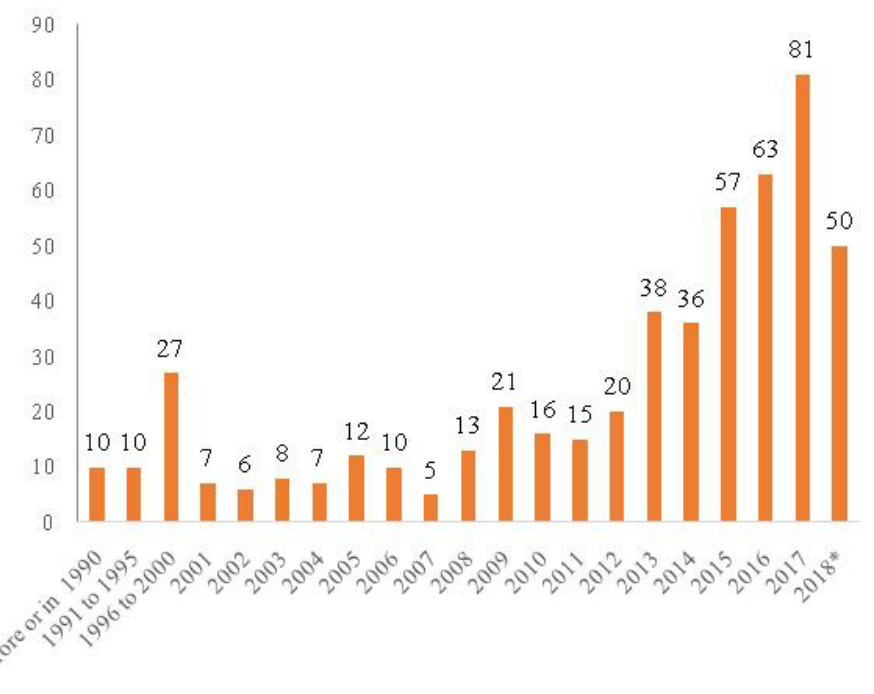

*: articles published in 2018 was up to the mid-April, hence the annual article in 2018 is incomplete.

Fig. 2. Distribution of journal articles by publication time

Fewer articles were published before 2000, especially before 1990. Therefore, these earlier articles were combined based on a five-year range from before 1990 to 2000. Articles published starting in 2001 are counted on the annual basis. It is seen from Fig. 2 that more articles have been published since 2012. Afterwards, the number of articles has been undergoing significant increase on a yearly basis. It is expected that more research work will be published in construction safety, which is an everlasting research domain in the field of construction engineering and management.

\subsection{Journal sources}

132 Besides the annual number of articles published, the journal sources of them were also

133 summarized. Setting the minimum number of articles and minimum citations at 3 and 20 respectively in VOSViewer, 20 out of totally 136 journals met the thresholds. According to the node and font sizes, it is seen in Fig. 3 that Journal of Construction Engineering and Management (JCEM) has been the most productive journal in terms of total number of 
137 publications, followed by Safety Science, and Automation in Construction. The colors and

138 connections lines indicate the inter-relatedness among journals, showing journals that have

139 cited each other's articles. For example, these journals have been actively citing each other:

140 JCEM, Safety Science, International Journal of Project Management, and Construction

141 Management and Economics.

142

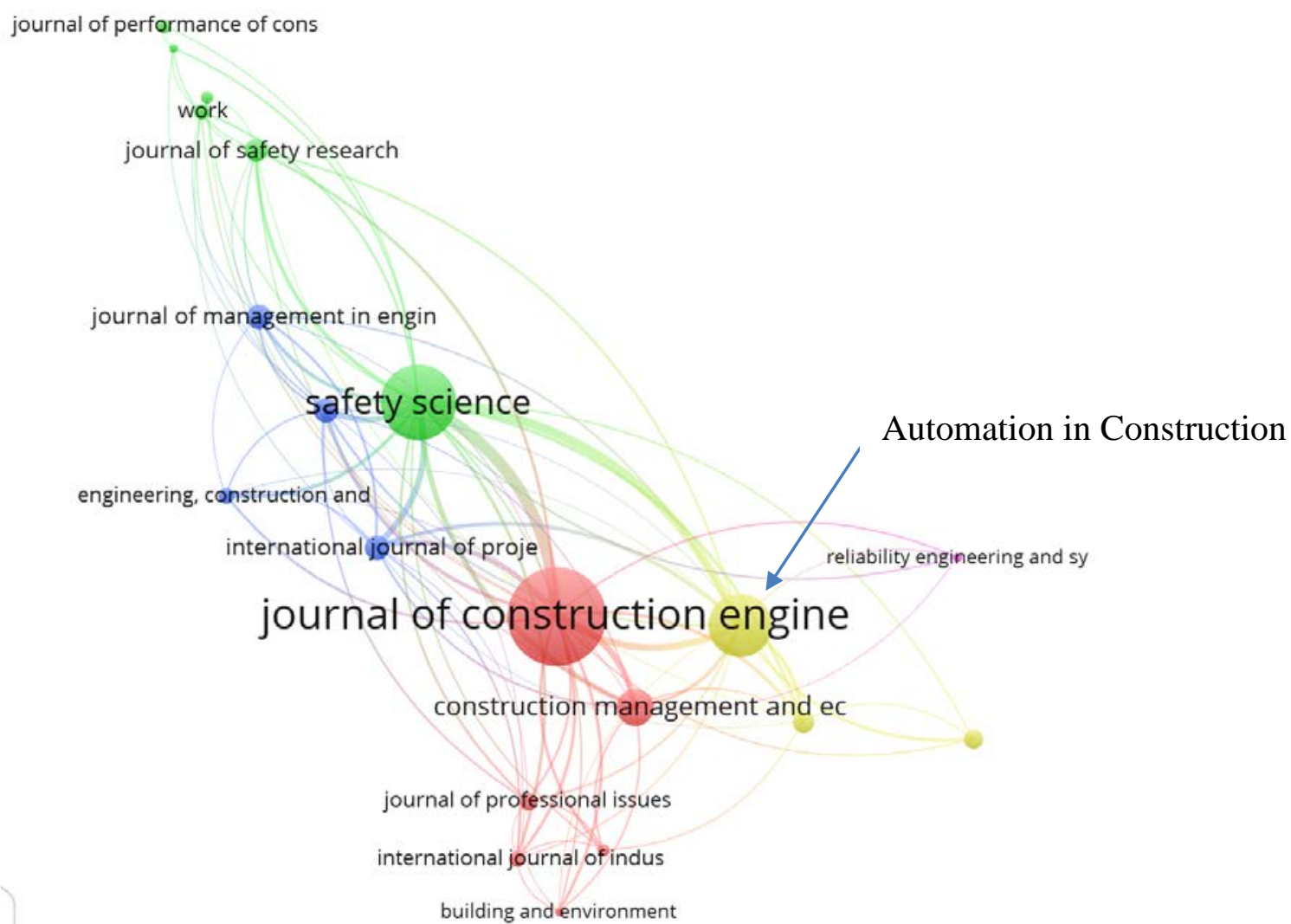

Note: 1. journal names may not be fully spelled out in VOSViewer; 2. Automation in Construction is denoted in

Fig. 3 outside the originally generated mapping in order to avoid the over-crowdedness of fonts.

Fig. 3. Visualization of journal sources that publish construction safety research

148 A more quantitative measurement of the influence of journals is provided in Table 1.

Table 1. Quantitative summary of journal impacts in construction safety research

\begin{tabular}{|l|r|r|r|l|l|l|}
\hline & $\begin{array}{l}\text { Number of } \\
\text { publications }\end{array}$ & $\begin{array}{l}\text { Total } \\
\text { Citation }\end{array}$ & $\begin{array}{l}\text { Norm. } \\
\text { Citation }\end{array}$ & $\begin{array}{l}\text { Avg. } \\
\text { Pub. } \\
\text { Yr. }\end{array}$ & $\begin{array}{l}\text { Avg. } \\
\text { Citation }\end{array}$ & $\begin{array}{l}\text { Avg. } \\
\text { Norm. } \\
\text { Citation }^{2}\end{array}$ \\
\hline Automation in Construction & 46 & 928 & 101.52 & 2015 & 20.17 & 2.21 \\
\hline $\begin{array}{l}\text { Reliability Engineering and } \\
\text { System Safety }\end{array}$ & 3 & 88 & 6.09 & 2013 & 29.33 & 2.03 \\
\hline
\end{tabular}




\begin{tabular}{|c|c|c|c|c|c|c|}
\hline $\begin{array}{l}\text { International Journal of } \\
\text { Project Management }\end{array}$ & 12 & 518 & 20.83 & 2011 & 43.17 & 1.74 \\
\hline Safety Science & 60 & 1964 & 102.21 & 2014 & 32.73 & 1.70 \\
\hline Building and Environment & 3 & 177 & 4.93 & 2004 & 59.00 & 1.64 \\
\hline $\begin{array}{l}\text { Journal of Computing in } \\
\text { Civil Engineering }\end{array}$ & 8 & 109 & 11.15 & 2015 & 13.63 & 1.39 \\
\hline $\begin{array}{l}\text { Accident Analysis and } \\
\text { Prevention }\end{array}$ & 12 & 181 & 15.83 & 2013 & 15.08 & 1.32 \\
\hline $\begin{array}{l}\text { Journal of Architectural } \\
\text { Engineering }\end{array}$ & 4 & 122 & 5.10 & 2002 & 30.50 & 1.27 \\
\hline $\begin{array}{l}\text { Journal of Construction } \\
\text { Engineering and } \\
\text { Management }\end{array}$ & 90 & 1855 & 103.87 & 2011 & 20.61 & 1.15 \\
\hline $\begin{array}{l}\text { Journal of Management in } \\
\text { Engineering }\end{array}$ & 12 & 134 & 13.19 & 2013 & 11.17 & 1.10 \\
\hline $\begin{array}{l}\text { Construction Management } \\
\text { and Economics }\end{array}$ & 21 & 391 & 21.40 & 2008 & 18.62 & 1.02 \\
\hline $\begin{array}{l}\text { International Journal of } \\
\text { Industrial Ergonomics }\end{array}$ & 6 & 191 & 5.83 & 2009 & 31.83 & 0.97 \\
\hline $\begin{array}{l}\text { Journal of Professional } \\
\text { Issues in Engineering } \\
\text { Education and Practice }\end{array}$ & 7 & 111 & 6.61 & 2013 & 15.86 & 0.94 \\
\hline Applied Ergonomics & 3 & 25 & 1.94 & 2015 & 8.33 & 0.65 \\
\hline Journal of Safety Research & 11 & 199 & 6.92 & 2011 & 18.09 & 0.63 \\
\hline $\begin{array}{l}\text { Engineering, Construction } \\
\text { and Architectural } \\
\text { Management }\end{array}$ & 6 & 88 & 3.48 & 2013 & 14.67 & 0.58 \\
\hline $\begin{array}{l}\text { Journal of Performance of } \\
\text { Constructed Facilities }\end{array}$ & 5 & 37 & 2.88 & 1998 & 7.40 & 0.58 \\
\hline $\begin{array}{l}\text { Journal of Civil Engineering } \\
\text { and Management }\end{array}$ & 9 & 46 & 4.65 & 2016 & 5.11 & 0.52 \\
\hline $\begin{array}{l}\text { American Journal of } \\
\text { Industrial Medicine }\end{array}$ & 4 & 76 & 1.78 & 2005 & 19.00 & 0.44 \\
\hline Work & 6 & 50 & 2.37 & 2007 & 8.33 & 0.39 \\
\hline
\end{tabular}

1: Ave. Pub. Yr denotes the average publication year of articles published in the given journal.

152 2: The Ave. Norm. Citation represents the normalized number of citations of a journal, document, author, or an organization. It equals the total number of citations divided by the average number of citations published in the same year. The normalization corrects the misinterpretation that older documents have more time to receive citations than more recent one(van Eck and Waltman, 2017). The Norm. Citation in Table 1 measures the citation of all the articles within the same journal, while the Ave. Norm. Citation represents the normalized citation per article, it is calculated by dividing the Nor. Citation by the number of articles. two journals(i.e., Automation in Construction, and Reliability Engineering and System Safety)

161 are most influential in construction safety research in terms of the Ave. Norm. Citation. In

162 terms of number of articles and total citations, Safety Science and JCEM are the two most 
measures the average year of publication of all articles published in the same journal, is a measurement of the recentness of published research from the given journal. It can be seen that the recentness of published articles vary somewhat significantly. Journals including Automation in Construction, Applied Ergonomics, Safety Science, and Journal of Civil Engineering and Management published articles in the construction safety domain actively. In contrast, other journals seem not continuing active in published articles in construction safety, such as Building and Environment, Construction Management and Economics, and Journal of Performance of Constructed Facilities.

\subsection{Keyword analysis}

173 Keywords represent core contents of existing studies and describe research topics within a given domain (Su and Lee, 2010). Co-occurrence of keywords demonstrate the inter-closeness among them. By using "Author Keywords" and "Fractional Counting" in VOSViewer recommended by van Eck and Waltman (2014), and by setting the minimum occurrence of keywords at 4 in VOSViewer, 64 out of the totally 1,260 keywords were initially selected. Further work was performed to remove general keywords, such as "construction safety", "safety”, “construction industry”, and "construction site”, etc. Some other keywords with the same semantic meaning, such as "BIM" and "Building Information Modeling", were combined. The second-round text mining of research keywords was performed to eliminate general keywords and to combine semantically consistent keywords. Finally, 29 keywords were generated from the science mapping shown in Fig. 4. These keywords have been more frequently used in previous research of construction safety, including "accident", "human factor", "risk", and "safety management”. The connection lines in Fig. 4 show the interrelatedness between a pair of keywords. For example, human factors closely related to employee' safety behavior, which covers studies focusing on correcting workers' unsafe behavior through proper safety management (Guo et al., 2017b). The keyword “design” highlights design for safety in construction, and it is found with close links to BIM and IT, 
Note: 1. 2. VOSViewer could only display small-cased letters. For example, "bim and it" means BIM and IT, or Building Information Modeling and Information Technology; 2. SEM in Figure.2 stands for structural equation modeling; HK is Hong Kong; AHP means analytic hierarchy process.

Fig. 4. Visualization of author keywords from the literature sample

Keywords in Fig.4 are divided into several clusters. Keywords within the same cluster in Fig.4 indicate the inter-relatedness among them. For example, BIM and information technologies are found with close relationship with design for safety, knowledge management, and ontology; safety behavior, human factors, and safety management are closely related to 
207 selected literature sample. These most frequently studied keywords include safety 208 management, accident, human factors, risk, and design. They are further summarized in Table

209 2, based on the occurrence of them in the literature sample, average year of publication (i.e., 210 Avg. Pub. Yr.), Average citation number (i.e., Avg. Citation), and average normalized citation 211 (i.e., Avg. Norm. Citation).

212 Table 2. Quantitative summary of journal impacts in construction safety research

\begin{tabular}{|l|l|l|l|l|}
\hline Keyword & Occurrence & Avg. Pub. Yr. & Avg. Citation & $\begin{array}{l}\text { Avg. Norm. } \\
\text { Citation }\end{array}$ \\
\hline Simulation & 4 & 2013 & 63.3 & 3.22 \\
\hline Fall & 4 & 2015 & 51.5 & 2.57 \\
\hline Leading Indicator & 5 & 2015 & 28.6 & 2.13 \\
\hline $\begin{array}{l}\text { Knowledge } \\
\text { Management }\end{array}$ & 4 & 2015 & 23.3 & 1.79 \\
\hline SEM & 8 & 2016 & 6 & 1.78 \\
\hline BIM and IT & 16 & 2016 & 16.3 & 1.68 \\
\hline Case Study & 4 & 2016 & 19 & 1.66 \\
\hline Contractor & 7 & 2009 & 24.4 & 1.63 \\
\hline Safety Behavior & 22 & 2016 & 18 & 1.48 \\
\hline Training and Education & 12 & 2014 & 23.6 & 1.42 \\
\hline Ontology & 6 & 2015 & 13 & 1.29 \\
\hline Design & 26 & 2014 & 26.3 & 1.27 \\
\hline Safety Management & 41 & 2014 & 13.7 & 1.23 \\
\hline Risk & 49 & 2014 & 19.5 & 1.21 \\
\hline Management System & 7 & 2011 & 59 & 1.2 \\
\hline VR & 7 & 2015 & 21.4 & 1.18 \\
\hline Hazard & 20 & 2015 & 11.6 & 1.17 \\
\hline Safety Climate & 21 & 2014 & 31.6 & 1.15 \\
\hline Human Factor & 46 & 2015 & 12.2 & 1.1 \\
\hline Safety Culture & 10 & 2014 & 28.7 & 1.03 \\
\hline Developing Country & 5 & 2010 & 7.4 & 1 \\
\hline Safety Performance & 19 & 2014 & 10.8 & 0.94 \\
\hline Accident & 51 & 2010 & 17.4 & 0.84 \\
\hline HK & 13 & 2011 & 28.2 & 0.81 \\
\hline Data Mining & 8 & 2015 & 6.6 & 0.8 \\
\hline Leadership & 5 & 2015 & 7 & 0.73 \\
\hline Safety Factor & 4 & 2013 & 16 & 0.54 \\
\hline Worker & 7 & 2017 & 0.4 & 0.27 \\
\hline AHP & 4 & 0.5 & 0.1 \\
\hline & & & \\
\hline
\end{tabular}



indicated from Table 2 that keywords with the highest occurrence do not necessarily have the highest Ave. Citation or Avg. Norm. Citation. For example, keywords with highest Avg. Norm.

Citation include simulation, fall, and leading indicators. It is indicated that studies focusing on applying simulation in safety planning (Goh and Askar Ali, 2016), accidents or risks caused by fall hazard (Cheung and Chan, 2012), or developing indicator system for evaluating safety performance or safety levels (Guo et al., 2017a) are likely to have higher impact in the research community of construction safety. The Avg. Pub. Yr. shows the recentness of keywords being studied and published. It is seen that most keywords listed in Table 2 are being studied in recent years except contractor, developing countries, and accident, which happen to be more traditionally studied keywords. These more emerging keywords include workers, SEM (i.e., structural equation modeling), AHP (i.e., analytical hierarchy process), BIM and IT, safety behavior, and case study. Observations of Fig. 4 and Table 2 could lead to the following clusters of keywords that represent the mainstream directions of research in construction safety:

1. Safety climate and safety culture, which represent proactive indicators of safety performance, are highly linked to safety behaviors of workers. Leadership from contractors and other stakeholders (e.g., owner) all have significant impacts on safety culture (Wu et al., 2016). These safety site issues have been emphasized from research conducted in Hong Kong such as Wong et al. (2009) and Ju and Rowlinson (2014). SEM (Sunindijo and Zou,

2. Information technology (e.g., BIM) has been playing a more significant role in safety 2012) has been one of the main researhc methods in the studies of safety climate and safety management. BIM has been displaying its influence in safety design and knowledge management (Tixier et al., 2016; Zhang et al., 2015a). Ontology is closely related to 
information technologies in developing knowledge-based safety system (Guo and Goh, 2017; Lu et al., 2015).

3. Besides BIM, using other latest digital technologies such as VR (i.e., virtual reality), AR (i.e., augmented reality), and game engine in safety management, including training (Sacks et al., 2013) by creating accident scenarios (Park and Kim, 2013). These acvitity games in VR or AR create the simulation representing site danger scenarios for safety training and education (Le et al., 2015).

4. Data analytics such as data mining are being applied in construction safety research, specifically inhazard assessment (Hsueh et al., 2013), accident prediction (Rivas et al., 2011), and managing safety database from accidents (Goh and Ubeynarayana, 2017). Therefore,data mining is widely applied in adopting leading indicator (e.g., safety compliance) for safety performance prediction (Salas and Hallowell, 2016).

5. Analytical hierarchy process(AHP) is being widely applied in safety risk management, including risk analysis (Ardeshir et al., 2016) and safety level assessment (Huang et al., 2018).

6. Safety management programs covering training and education form a key part in the management system. Various studies (Chen and Jin, 2012; Li et al., 2018b) can be found introducing effective site safety programs addressing human factors and hazard assessment.Human factors in safety is an issue that has been idenfied to cause management failure (Kim et al., 2014).

7. Case study is another main research methodology is evaluate and test the effectiveness of newly developed management system or process, such as risk assessment model (Ning et al., 2018), worker safety behavior monitoring system (Li et al., 2015a), and decisionmaking in safety planning (Priemus and Ale, 2010). 
263 Continued from the keyword analysis, the literature can be further divided into two 264 subsamples according to their years of publication. A total of 115 articles were published before 265 2009, with the first one appearing in Scopus in 1982. The remaining 398 articles were published 266 during or after 2009. The separate mapping of keywords are demonstrated in Fig. 5 and Fig. 6, 267 which allow the comparison of mainstream research keywords between the two subsamples 268 (i.e., from the recent decade and before 2009). Compared to the keywords in the recent ten 269 years, fewer keywords are found in Fig. 5. Literature before 2009 focused more on accidents, which were used as the main safety performance measurement (Ai Lin Teo and Yean Yng 271 Ling, 2006). The causes of higher accident rates were evaluated, stressing the importance of 272 safety training (Enshassi et al., 2007) and safety climate (Strahan et al., 2008). Compared to 273 these earlier research topics in construction safety, more recent keywords emerging in the 274 recent decade include "BIM and IT", "VR” (i.e., Virtual Reality), "SEM” (i.e., structural 275 equation modeling), “data mining”, and “AHP” (i.e., analytic hierarchy process). It is indicated 276 that BIM and more advanced decision making tools (e.g., AHP) have been gaining wider 277 applications in construction safety management in recent years. BIM, as the recently emerging 278 digital technology, is gaining more application and research in assisting design for safety. Other 279 digital technologies, such as VR, are also gaining its popularity in safety training, as discussed 280 by Li et al. (2018a). 
legislation

risk

hazard

intervention

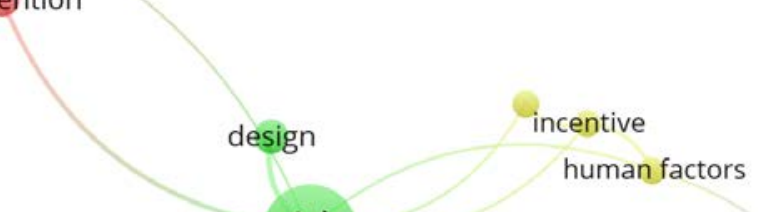

accident

contract

owner

safety program

Fig.5. Visualization of author keywords from the literature sample published before 2009

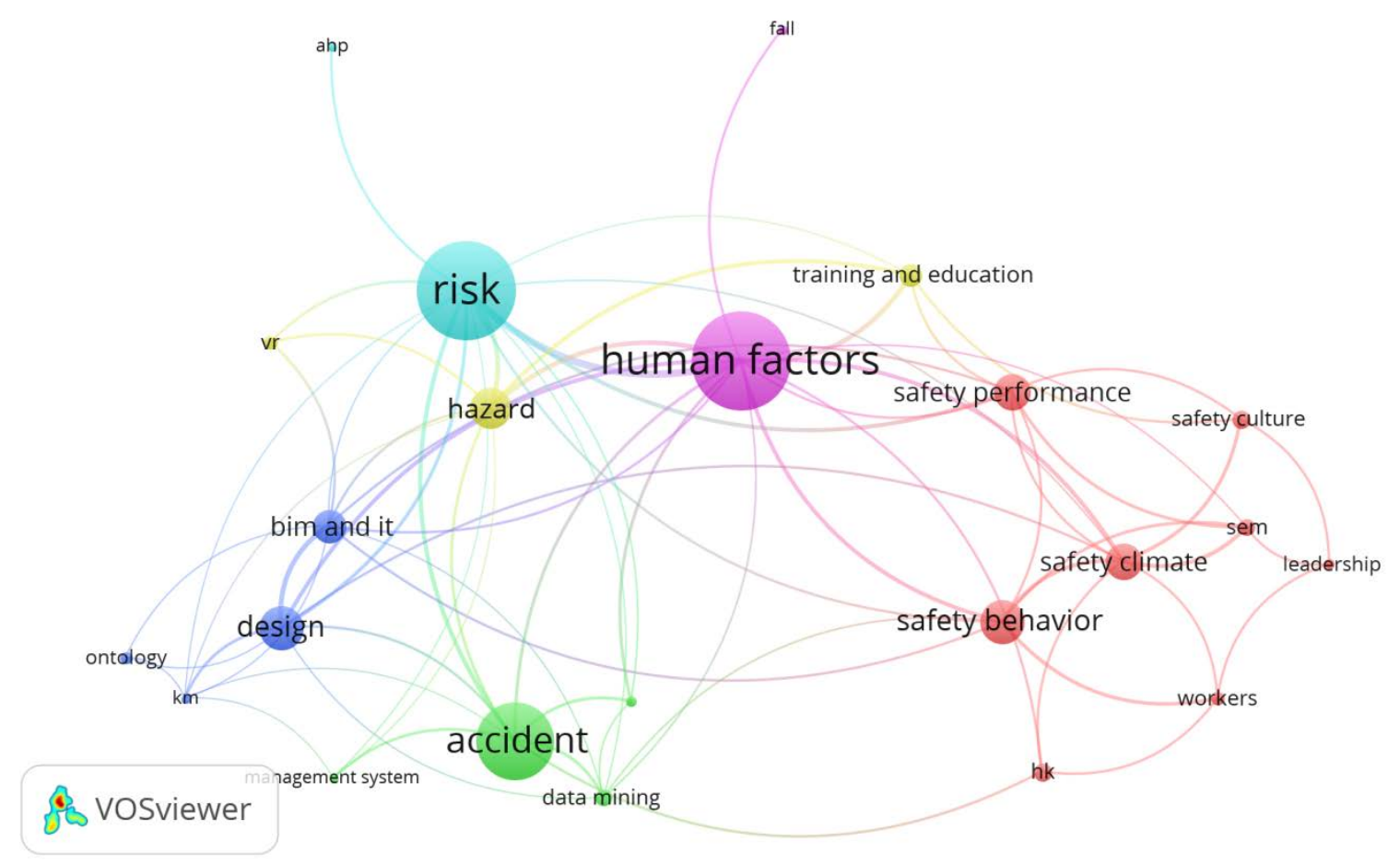

Note: VR stands for virtual reality

Fig. 6. Visualization of author keywords from the literature sample published following 2009

\subsection{Scholars in construction safety}

288 Citation analysis was conducted using VOSViewer. In this study, a minimum number of documents and minimum citation number of a scholar were set at 5 and 30 respectively. As a result, a total of 35 scholars met the thresholds and visualized in Fig.7. 


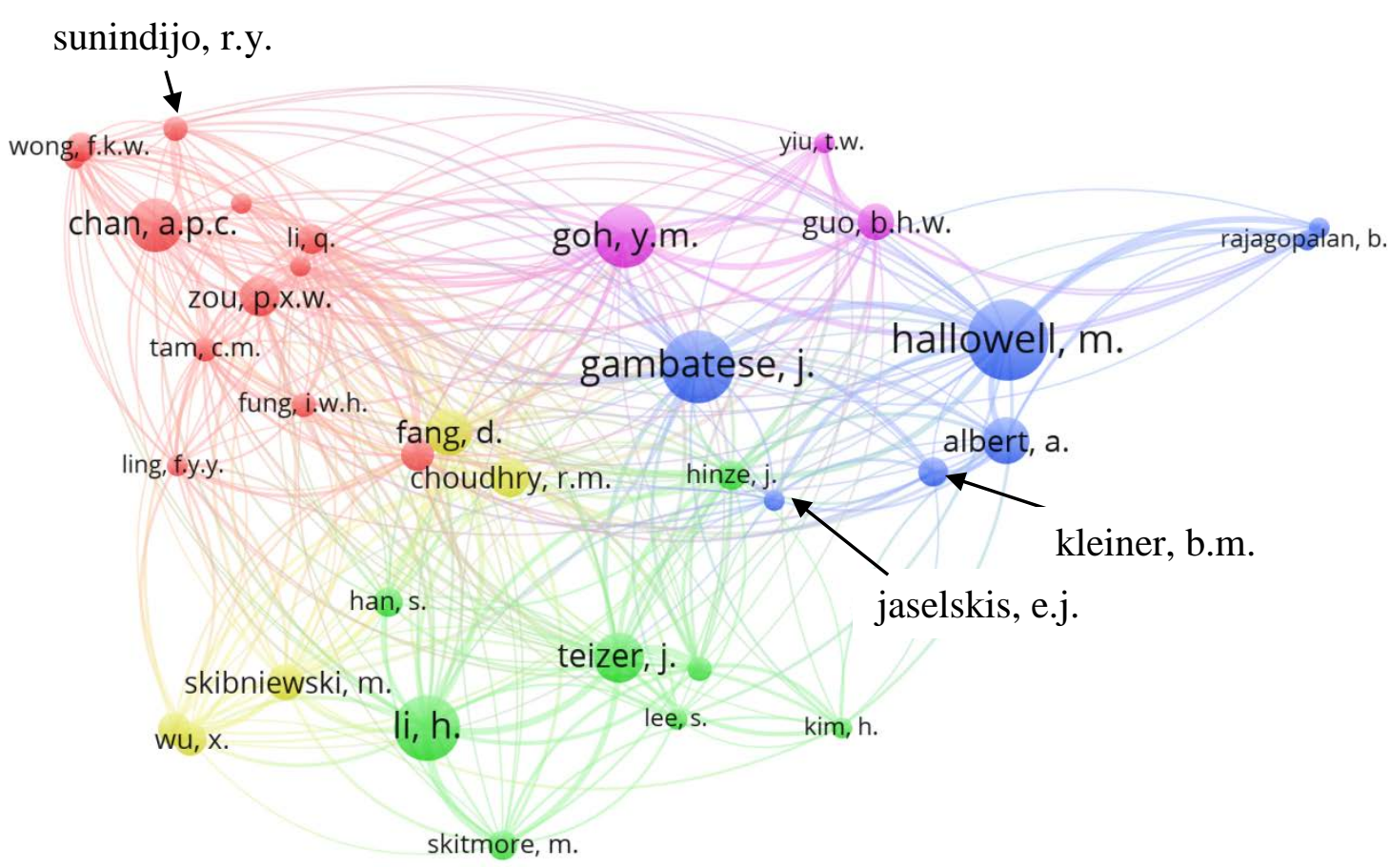

Fig.7. Visualization of scholars in the research community of construction safety

The font and circle size for each scholar indicate their number of publications in construction safety. Scholars displayed in Fig.7 were divided into different clusters according to their own citation networks. For example, Zou, P.X.W., Chan, A.P.C., Li,Q., Wong, F.K.W., Tam, C.M.,

297 Sunindijo, R.Y., Ling, F.Y.Y., and Fung, I.W.H occurred to be in the same cluster, indicating

298 their mutual influence by citing each other’s work. The influence among scholars can be further measured by the distance and connection lines shown in Fig.7. For example, Fang, D. and Choudhry, R.M. can be found with strong linkage in construction safety research. The quantitative analysis of scholars' academic influence is provided in Table 3.

Table 3. Quantitative summary of impacts of scholars in the academic community of construction safety

\begin{tabular}{|l|r|r|r|l|r|r|}
\hline Scholar name & $\begin{array}{l}\text { Number } \\
\text { of articles }\end{array}$ & $\begin{array}{l}\text { Total } \\
\text { citation }\end{array}$ & $\begin{array}{l}\text { Norm. } \\
\text { Citation }\end{array}$ & $\begin{array}{l}\text { Ave. } \\
\text { Pub. } \\
\text { Yr. }\end{array}$ & $\begin{array}{l}\text { Average } \\
\text { citation }\end{array}$ & $\begin{array}{l}\text { Ave. Norm. } \\
\text { Citation }\end{array}$ \\
\hline Zhang, S. & 6 & 334 & 22.56 & 2015 & 55.67 & 3.76 \\
\hline Teizer, J. & 13 & 712 & 37.83 & 2013 & 54.77 & 2.91 \\
\hline Li, H. & 17 & 148 & 38.40 & 2015 & 8.71 & 2.26 \\
\hline Lee, S. & 5 & 100 & 11.06 & 2015 & 20.00 & 2.21 \\
\hline
\end{tabular}




\begin{tabular}{|l|r|r|r|r|r|r|} 
Yiu, T.W. & 5 & 52 & 10.34 & 2016 & 10.40 & 2.07 \\
\hline Tam, C.M. & 6 & 345 & 11.92 & 2004 & 57.50 & 1.99 \\
\hline Hinze, J. & 7 & 449 & 13.84 & 2009 & 64.14 & 1.98 \\
\hline Tixier, A.J.-P. & 5 & 53 & 9.87 & 2016 & 10.60 & 1.97 \\
\hline Fung, I.W.H. & 6 & 204 & 11.42 & 2007 & 34.00 & 1.90 \\
\hline Rajagopalan, B. & 5 & 44 & 9.43 & 2016 & 8.80 & 1.89 \\
\hline Jaselskis, E.J. & 5 & 184 & 9.25 & 2003 & 36.80 & 1.85 \\
\hline Skitmore, M. & 7 & 49 & 12.16 & 2016 & 7.00 & 1.74 \\
\hline Wu, X. & 8 & 105 & 13.80 & 2016 & 13.13 & 1.73 \\
\hline Skibniewski, M. & 9 & 128 & 15.05 & 2016 & 14.22 & 1.67 \\
\hline Zhou, Z. & 5 & 98 & 8.32 & 2014 & 19.60 & 1.66 \\
\hline Zhang, L. & 8 & 104 & 13.17 & 2016 & 13.00 & 1.65 \\
\hline Fang, D. & 12 & 658 & 17.89 & 2012 & 54.83 & 1.49 \\
\hline Choudhry, R.M. & 10 & 571 & 14.62 & 2011 & 57.10 & 1.46 \\
\hline Li, Q. & 7 & 101 & 10.23 & 2015 & 14.43 & 1.46 \\
\hline Mohamed, S. & 8 & 399 & 11.42 & 2010 & 49.88 & 1.43 \\
\hline Kim, H. & 5 & 60 & 7.12 & 2015 & 12.00 & 1.42 \\
\hline Hallowell, M. & 22 & 380 & 29.22 & 2015 & 17.27 & 1.33 \\
\hline Gambatese, J. & 19 & 559 & 23.55 & 2012 & 29.42 & 1.24 \\
\hline Guo, B.H.W. & 9 & 53 & 10.98 & 2017 & 5.89 & 1.22 \\
\hline Kleiner, B.M. & 7 & 89 & 8.13 & 2015 & 12.71 & 1.16 \\
\hline Albert, A. & 12 & 113 & 13.86 & 2016 & 9.42 & 1.16 \\
\hline Ling, F.Y.Y. & 5 & 188 & 5.68 & 2010 & 37.60 & 1.14 \\
\hline Han, S. & 7 & 89 & 7.16 & 2015 & 12.71 & 1.02 \\
\hline Goh, Y.M. & 16 & 160 & 13.17 & 2015 & 10.00 & 0.82 \\
\hline Zou, P.X.W. & 115 & 7.61 & 2014 & 11.50 & 0.76 \\
\hline Sunindijo, R.Y. & 7 & 5 & 4.55 & 2013 & 12.33 & 0.76 \\
\hline Hon, C.K.H. & 37 & 3.75 & 2016 & 7.40 & 0.75 \\
\hline Chan, A.P.C. & 113 & 8.64 & 2013 & 8.07 & 0.62 \\
\hline Wong, F.K.W. & 44 & 4.04 & 2013 & 6.29 & 0.58 \\
\hline Irizarry, J. & 42 & 2.83 & 2014 & 8.40 & 0.57 \\
\hline & & & & & \\
\hline
\end{tabular}

Scholars listed in Table 3 are based on their Ave. Norm. Citation. It is seen in Table 3 that Zhang, S, although with only six articles in total from the literature sample, has the highest

307 influence measured by the Ave. Norm. Citation. In terms of Norm. Citation representing the 308 average citation per year of all personal publications, Teizer, J., Li, H., and Hallowell, M. top 309 the table. In terms of total citation and average citation, Fang, D., Gambatese, J., Choudhry,

310 R.M., and Hinze, J. can be considered scholars with the highest contribution to the academic 311 community of construction safety. Hallowell, M., Gambatese, J.,Li, H., Goh, Y.M., and Chan, 
312 A.P.C. can be considered as most productive scholars measured by their number of publications

313 in this literature sample. The Ave. Pub. Yr. infers the recentness of publications of the scholar.

314 As seen in Table 3, most scholars remain active in the research domain of construction safety,

315 except Tam, C.M., Fung, I.W.H., Jaselskis, E.J., and Hinze, J., whose values of Ave. Pub. Yr.

316 are all before 2010.

317

318

319

320

321

322

\subsection{Document analysis}

Setting the minimum citation number at 50 in filtering the literature sample, a total of 49 articles met the requirements. These most influential articles in terms of normalized citation are listed in Table 4.

Table 4. Summary of highly cited journal articles in construction safety

\begin{tabular}{|c|c|c|c|}
\hline Article & Title & $\begin{array}{l}\text { Total } \\
\text { citation }\end{array}$ & $\begin{array}{l}\text { Normalized } \\
\text { citation }\end{array}$ \\
\hline $\begin{array}{l}\text { Zhang et al., } \\
\text { (2013) }\end{array}$ & $\begin{array}{l}\text { Building Information Modeling (BIM) and Safety: } \\
\text { Automatic Safety Checking of Construction Models } \\
\text { and Schedules }\end{array}$ & 201 & 9.82 \\
\hline $\begin{array}{l}\text { Zhang et al. } \\
(2015 b)\end{array}$ & $\begin{array}{l}\text { BIM-based fall hazard identification and prevention in } \\
\text { construction safety planning }\end{array}$ & 51 & 4.89 \\
\hline $\begin{array}{l}\text { Teizer et al. } \\
\text { (2010) }\end{array}$ & $\begin{array}{l}\text { Autonomous pro-active real-time construction worker } \\
\text { and equipment operator proximity safety alert system }\end{array}$ & 164 & 4.73 \\
\hline $\begin{array}{l}\text { Hinze et al. } \\
(2013)\end{array}$ & Leading indicators of construction safety performance & 86 & 4.20 \\
\hline $\begin{array}{l}\text { Mohamed } \\
\text { (1999) }\end{array}$ & $\begin{array}{l}\text { Empirical investigation of construction safety } \\
\text { management activities and performance in Australia }\end{array}$ & 53 & 4.08 \\
\hline $\begin{array}{l}\text { Lee et al. } \\
\text { (2012) }\end{array}$ & $\begin{array}{l}\begin{array}{l}\text { RFID-Based Real-Time Locating System for } \\
\text { Construction Safety Management }\end{array} \\
\end{array}$ & 55 & 4.07 \\
\hline $\begin{array}{l}\text { Cheng and } \\
\text { Teizer (2013) }\end{array}$ & $\begin{array}{l}\text { Real-time resource location data collection and } \\
\text { visualization technology for construction safety and } \\
\text { activity monitoring applications }\end{array}$ & 82 & 4.01 \\
\hline $\begin{array}{l}\text { Choudhry et } \\
\text { al. (2007) }\end{array}$ & $\begin{array}{l}\text { The nature of safety culture: A survey of the state-of- } \\
\text { the-art }\end{array}$ & 222 & 3.85 \\
\hline $\begin{array}{l}\text { Tam et al. } \\
\text { (2002) }\end{array}$ & $\begin{array}{l}\text { Non-structural fuzzy decision support system for } \\
\text { evaluation of construction safety management system }\end{array}$ & 63 & 3.53 \\
\hline $\begin{array}{l}\text { Hallowell and } \\
\text { Gambatese } \\
\text { (2009) }\end{array}$ & Construction safety risk mitigation & 80 & 3.33 \\
\hline $\begin{array}{l}\text { Gürcanli and } \\
\text { Müngen } \\
\text { (2009) }\end{array}$ & $\begin{array}{l}\text { An occupational safety risk analysis method at } \\
\text { construction sites using fuzzy sets }\end{array}$ & 79 & 3.29 \\
\hline $\begin{array}{l}\text { Tam et al. } \\
(2004)\end{array}$ & $\begin{array}{l}\text { Identifying elements of poor construction safety } \\
\text { management in China }\end{array}$ & 167 & 3.27 \\
\hline $\begin{array}{l}\text { (Carter and } \\
\text { Smith, 2006) }\end{array}$ & Safety hazard identification on construction projects & 144 & 2.97 \\
\hline
\end{tabular}




\begin{tabular}{|c|c|c|c|}
\hline (Behm, 2005) & $\begin{array}{l}\text { Linking construction fatalities to the design for } \\
\text { construction safety concept }\end{array}$ & 172 & 2.94 \\
\hline $\begin{array}{l}\text { Choudhry and } \\
\text { Fang (2008) }\end{array}$ & $\begin{array}{l}\text { Why operatives engage in unsafe work behavior: } \\
\text { Investigating factors on construction sites }\end{array}$ & 188 & 2.87 \\
\hline $\begin{array}{l}\text { Pinto et al. } \\
\text { (2011) }\end{array}$ & $\begin{array}{l}\text { Occupational risk assessment in construction industry } \\
\text { - Overview and reflection }\end{array}$ & 82 & 2.66 \\
\hline $\begin{array}{l}\text { Jaselskis et al. } \\
\text { (1996) }\end{array}$ & $\begin{array}{l}\text { Strategies for achieving excellence in construction } \\
\text { safety performance }\end{array}$ & 141 & 2.53 \\
\hline $\begin{array}{l}\text { Gambatese et } \\
\text { al. (1997) }\end{array}$ & Tool to design for construction worker safety & 82 & 2.43 \\
\hline $\begin{array}{l}\text { Garrett and } \\
\text { Teizer (2009) }\end{array}$ & $\begin{array}{l}\text { Human factors analysis classification system relating } \\
\text { to human error awareness taxonomy in construction } \\
\text { safety }\end{array}$ & 54 & 2.25 \\
\hline $\begin{array}{l}\text { Kartam } \\
(1997)\end{array}$ & $\begin{array}{l}\text { Integrating safety and health performance into } \\
\text { construction CPM }\end{array}$ & 76 & 2.25 \\
\hline $\begin{array}{l}\text { Aksorn and } \\
\text { Hadikusumo } \\
\text { (2008) }\end{array}$ & $\begin{array}{l}\text { Critical success factors influencing safety program } \\
\text { performance in Thai construction projects }\end{array}$ & 133 & 2.03 \\
\hline
\end{tabular}

323

It should be noticed that not all filtered 49 articles are presented in Table 4 but only with normalized citation over 2.00. Other articles such as Gambatese et al. (2005) and Gambatese et al. (2008) although with high total citation, the normalized citation are below 2.00. The study of Zhang et al. (2013) focusing on BIM applied in automatic safety checking has received significantly higher normalized citation than the other articles. It is indicated from Table 4 that these most influential articles generally applied ICT (e.g., BIM and real-time data capturing) in safety management. Other articles representing more traditional safety research include safety culture (Choudhry et al., 2007), safety indicators (Hinze et al., 2013), safety behavior (Choudhry and Fang, 2008), hazard identification (Carter and Smith, 2006), risk assessment (Pinto et al., 2011), safety program and its critical factors (Aksorn and Hadikusumo, 2008), design for safety (Gambatese et al., 1997), and safety performance (Jaselskis et al., 1996).

\section{Qualitative discussions}

Following up the bibliometric analysis and science mapping of the selected literature sample, the in-depth qualitative discussion now focused on summarizing the main research topics within the theme of construction safety, identifying the existing research gaps, as well 
341 as proposing a framework by linking existing research topics into future recommended directions.

\subsection{Summary of main research topics in construction safety}

The seven main clusters of keywords identified from Fig.2 are not separated. Instead, keywords from different clusters could have strong links. For example, BIM and VR are both digital technology and are linked to each other to be applied in safety management, although VR is more commonly applied in safety education and training, while BIM can be more widely applied in various safety management activities such as design for safety and site planning (Choi et al., 2017; Malekitabar et al., 2016). Continued from the clustering of keywords in Section 3.2, the mainstream research topics in construction safety can be summarized below.

\subsubsection{Safety climate and safety culture}

There have been multiple studies focusing on developing, testing, and evaluating the framework of safety climate or safety culture (Ardeshir and Mohajeri, 2018; Chen et al., 2018), as well as linking them to safety performance measurement (Alruqi et al., 2018). Key indicators within safety climate (Alruqi et al., 2018; Newaz et al., 2018) is being kept updated and validated using statistical methods such as SEM (Zhang et al., 2018a). Commonly defined elements within safety climate include but are not limited to management commitment (Zahoor et al., 2017), co-workers caring and communication (Gao et al., 2016), and safety behavior (Zhang et al., 2017). A high attention within safety climate has been paid on workers, such as worker behavior (Jiang et al., 2018), safety compliance (Xia et al., 2018), and perceptions (Stiehl and Forst, 2018).

Multiple studies (Guldenmund, 2000; Marquardt et al., 2012) indicate that safety climate forms a core part of safety culture (Zou and Sunindijo 2015). Safety culture studies have been much focusing on the organization level (Goncalves Filho and Waterson, 2018), not just within contractors (Karakhan et al., 2018) but also other stakeholders(Wu et al., 2015a). Modeling 
safety culture can be found in various existing studies (Koch, 2013; Trinh et al., 2018). Much work (e.g., Choudhry et al., 2009; Wen Lim et al., 2018) has addressed the relationships among safety climate, safety culture, and safety performance. For example, Teo and Feng (2009) found that safety climate impacted safety culture in terms of psychological, situational/environmental and behavioral aspects, and the assessment of safety climate could predict safety culture, which could further influences safety performance (Choudhry et al., 2009).

\subsubsection{Information and communication technology in safety management} construction industry. BIM has displayed its role in safety management as showcased in existing studies (Chen and Liu, 2015; Zhang et al., 2015b), such as training for workers in offsite construction by increasing workers' hazard awareness (Li et al., 2015b), visualization of scaffolding and safety facilities for accident prevention (Liu et al., 2017), and developing databases of near-miss events on-site (Shen and Marks, 2016). Besides BIM, VR has shown its influence in safety training and education (Pedro et al., 2016), specifically in hazard recognition and risk identification in the virtual environment (Perlman et al., 2014) and improving the communication between designer and builder (Sacks et al., 2015). Multiple other digital tools or media such as sensor-based technology, 3S (GIS/GPS/RS) technology, radio frequency identification (RFID) as mentioned by Zhou et al. (2013) could be integrated to assist construction safety management. For example, Aguilar and Hewage (2013) developed a realtime safety indicator from a centralized safety database with ICT to assist site managers' site decision making; Cheng and Teizer (2013) applied real-time data collection, processing, and visualization through remote sensing and VR to monitor site safety condition; Zou et al. (2017a) developed a cloud-based safety information and communication system to improve road construction safety.

\subsubsection{Workers' safety perception and behavior}



ICTs. For instance, Park et al. (2016) created and evaluated a proximity detection and alert system using Bluetooth sensing technology aiming to protect the health and safety of pavement workers; Yi and Wang (2017) applied a mixed-integer linear programming approach to optimize workers' site work schedule under hot outdoor weather condition; Workers' site condition exposed to unpleasant weather (e.g., hot temperature) has caught the attention of multiple researchers (Han et al., 2018; Yi and Chan, 2017). More studies have focused on workers’ demographic or subgroup features, such as minority or immigration workers (Chan et al., 2017; Lyu et al., 2018; Suo and Zhang, 2017; Wasilkiewicz et al., 2016), workers from difference experience levels (Han et al., 2018), and workers from different building trades

402 (Chen and Jin, 2015). The causes of workers' variation in their safety perception, attitudes, 403 behavior, and performance have been linked to dimensions within safety climate such as safety awareness and co-workers attitudes (Choudhry and Fang, 2008), safety program (Bigelow et al., 1998), company size (Guo et al., 2018b), and management methods (Guo et al., 2018c). The causal connection analysis conducted by Winge et al. (2019) showed that supervision strongly affected workers’ safety actions.

408

\subsubsection{Safety management system}

There is a significant correlation between management commitment and safety performance

411 (Abudayyeh et al., 2006). An effective safety program incorporating the management 412 commitment as well as training and education could ultimately lead to improved safety 413 performance (Chen and Jin, 2012). Participation in safety management should not be limited 414 to contractors, but other stakeholders such as the owner (Huang and Hinze, 2006). Researchers 415 have been working on developing a safety management plan that a typical contractor can adopt 416 (Shahbodaghlou and Haven, 2000). Key factors within safety management program have been 
studied to explore their inter-relationships. For instance, Bavafa et al. (2018) found that safety commitment and responsibilities, subcontractors and personnel's selection, safety supervisor and professionals, plan for safety, and employee involvement were key critical factors to have an improved safety program. Similarly, a total of 16 critical factors influencing the success of a construction safety program was identified and tested by Aksorn and Hadikusumo (2008).

Similar studies investigating key factors for effective implementation of safety management system can be found in Pereira et al. (2018) and Yiu et al. (2018). The subcontracting nature of the construction industry indicates that an effective safety program should gain the jointeffort among multiple organizations to maintain consistent safety compliance, which could be evaluated based on behavior-based safety rules (Guo et al., 2018a). The conflicting objective between site productivity and safety as indicated by Sandberg and Albrechtsen (2018) needs to be properly handled in the safety reporting process, which should be part of an effective management program.

\subsubsection{Hazard identification, accident causation, and risk management in safety}

(Pereira et al., 2018) found that the highest-priority accident precursors are workers' failure to identify hazards and negligence of hazards. Hazard identification, accident investigation, and risk assessment have been a long-standing research topics within construction safety management. Earlier studies have been focusing on proper protective equipment (Lette et al., 2018), accident types and physical barrier elements (Winge and Albrechtsen, 2018), causes of accidents or incidents (Ale et al., 2008; Haslam et al., 2005; Manu et al., 2010), safety training (Jeelani et al., 2018), and effective management program (Li et al., 2018b). More recent studies

438 (Choe and Leite, 2017; Malekitabar et al., 2016; Park et al., 2017; Yi et al., 2015; Zou et al., 2017b) have been emphasizing on ICT (e.g., BIM) as the digital approach in mitigating safety risks. Safety should be considered in the design stage (Teo et al., 2016), when hazards can be

441 identified in the ontology-based semantic modeling (Zhang et al., 2015a). 


\subsection{Research gaps in construction safety}

443

444

445

446

447

448

450

451

452

453

454

455

456

457

458

459

460

461

462

463

464

465

466

\subsubsection{An adaptable safety climate and safety culture framework}

The scale of safety climate research cross different levels, including industry, organization, site, and group levels (Chen et al., 2018). An adaptable or robust safety climate indicator system that can be applied in different sites or groups could be further developed, due to the heterogeneous features and complexity of construction projects. Similarly, Trinh et al. (2018) indicated that a resilient safety culture model should lead to high safety performance regardless of the changing complexity levels or conditions of construction projects. There is a gap of how such an indicator system in safety climate and the safety culture model can be more widely applicable in inter-organizational context and also in different project sites and subgroups of site employees. The indicators within safety climate and culture are not completely consistent among studies (Li et al., 2017; McCabe et al., 2017; Wu et al., 2015b), possibly due to the general safety culture in the industry level within a country or region’s context. Most existing studies (Chen et al., 2013; Zahoor et al., 2017) on safety climate and safety culture have been set on the context of a specific country, with limited extending the framework for cross-country validation or international comparison. Nevertheless, it is an important issue of implementing safety practice in international construction projects (Gao et al., 2018) and sharing the safety experience crossing countries (Gibb et al., 2014).

\subsubsection{ICT application in construction safety}

A review of these studies applying ICT in site safety indicates that most studies have focused on fall hazard identification (Melzner et al., 2013; Qi et al., 2014; Wang et al., 2015; Zhang et al., 2015b). As there are multiple common hazards on construction sites, such as fall, struckby, caught-in-between, and electrocution identified as Focus4Hazard by (OSHA, 2011). More ICT-based platforms, prototypes, or user interfaces could be extended to incorporate these main hazards on-site. A step forward of the existing research in applying BIM for safety hazard 
identification could be to create a prototype that automatically updates hazard assessment the

468

469

470

471

472

473

474

475

476

477

478

479

480

481

482

483

484

485

486

487

488

489

490

491 as-planned BIM as project progresses. Hazard assessment is defined as the occurrence, severity, and risk level according to existing safety database. More importantly, the established ICT-based prototype or frameworks (Teo et al., 2016) could be further tested with more realworld cases, including its user friendliness, users’ readiness, acceptance, and easiness for safety communication. From the technical perspective, the interoperability among multiple ICT tools (e.g., BIM and wireless sensing) to allow information exchange during real-time data collection and processing needs to be further studied.

\subsubsection{Workers' safety issues}

Subgroup factors of workers (e.g., age and site experience level) could cause different safety perceptions (Han et al., 2018), further leading to varied safety behavior (Li et al., 2015c), and ultimately safety performance (Chen et al., 2018). Besides these internal influence factors, there have been limited studies of how the external conditions of jobsites (e.g., lighting, temperature, spatial crowdedness) affect workers safety perception, behavior, and performance. Workers' safety perceptions towards site hazards and risks could be further linked to their safety cognition pattern (Liu, 2018; Marquardt et al., 2012). There have been limited studies linking their cognition patterns (e.g., safety knowledge-based, prior scenariobased, and basic assumption-based) into safety perceptions. Furthermore, the cognition psychology or cognitive model, although having been studied in other industries or fields such as traffic (Aksan et al., 2017; Lyu et al., 2017), have not been sufficiently applied in construction safety, especially in workers' safety perception or behavior (Fang et al., 2016).

\subsubsection{Adaptability of safety management system}

Similar to the studies in safety climate and safety culture, the effectiveness of existing safety programs should also be tested in different organization sizes, different project conditions, and different country contexts as indicated by Bavafa et al. (2018) and Oswald et al. (2018). More 
492 recent studies (Kim et al., 2019) have proposed ICT (e.g., Internet-of-Things) in safety

493 management. However, many of these studies stay in the framework stage, more solid work

494 needs to be conducted in the future to establish, test, validate, and finally apply the proposed

495 ICT-based safety management programs. The longer-term effects of specific safety programs

496 on safety climate and safety performance could be further investigated (Jeschke et al., 2017).

497 The latest research by Niu et al. (2018) proposed the artificial intelligence that harnesses the 498 power of smart features within the newly developed system, which was named as the "third 499 wave” construction safety management, following “first wave” of safety management focusing 500 on "hard" equipment and the "second wave" highlighting the "soft" managerial safety (e.g., 501 safety culture).

502 4.2.5. Hazard recognition and risk mitigation

503 Generally speaking, safety research in hazard recognition and risk mitigation could be 504 categorized as managerial studies which focus on human factors (e.g., workers’ characteristics) and information technologies (e.g., BIM). There have been more emerging studies by applying

506 ICT tools in safety hazard identification and risk assessment such as (Qi et al., 2014) and (Yi 507 et al., 2015). Digital technologies such as BIM and VR are being applied in the pre-construction 508 stage to enhance workers' skills in identifying and assessing hazards. However, there have been insufficient studies in integrating ICT to monitor workers' safety behavior and update it for safety managers. It is known that ICT could assist design for safety in pre-construction stages.

511 As the construction project progresses, there could be updated BIM model by incorporating 512 workers' latest activities through site data collected by wireless sensing technologies. 513 Therefore, safety managers are kept updated with workers’ physical status and work progress.

514 Safety managers can also be informed of potential hazards that might hold workers at risk as 515 workers’ tasks change or the project progresses. More future work can be performed in bridging 516 the manager monitoring of workers' safety and workers' own self-awareness of safety hazards 
517 through ICT tools. Besides the technological innovation, the readiness of workers and

518 management personnel to adopt newly developed ICT platforms should also be considered.

\section{$519 \quad$ 4.3.Research trends in construction safety}

520 Based on the keyword analysis, qualitative discussions of mainstream research areas within

521 construction, as well as gap analysis, a research framework suggesting future directions is

522 proposed in Fig.8.

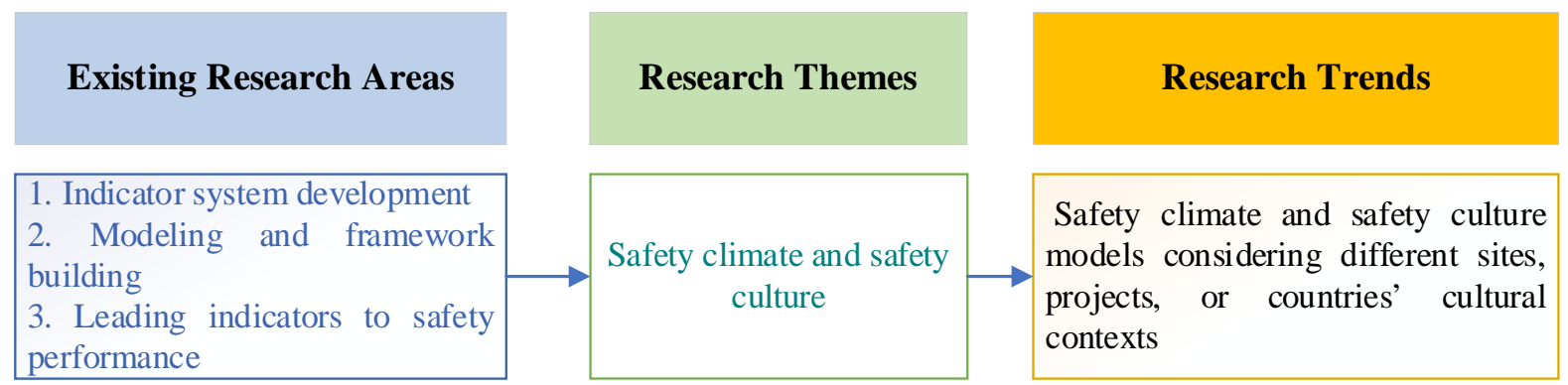

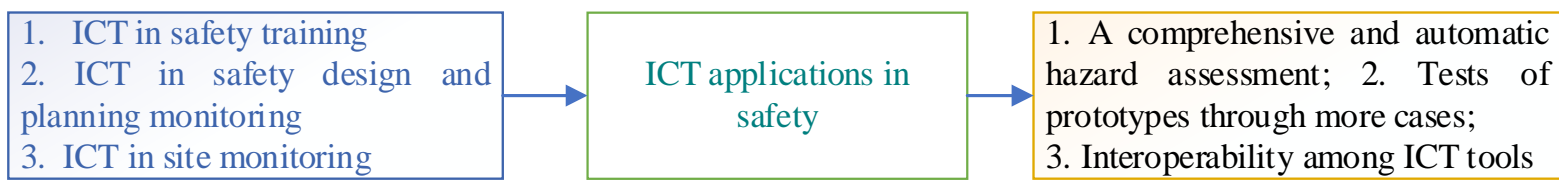

\begin{tabular}{|l|l|l|}
\hline $\begin{array}{l}\text { 1. Adverse site condition; } \\
\text { 2. Workers subgroup or } \\
\text { demographic factors; } \\
\text { 3. Critical success factors; }\end{array} \quad$ Workers' safety & $\begin{array}{l}\text { 1. Effects of subgroup factors on } \\
\text { safety perception and behavior; } \\
\text { 2. Cognitive models of workers' } \\
\text { safety perception and behavior }\end{array}$ \\
\hline
\end{tabular}

\begin{tabular}{|c|c|c|}
\hline $\begin{array}{l}\text { 1. Critical success factors of } \\
\text { safety program; } 2 . \quad \text { The } \\
\text { relationship between safety } \\
\text { management and performance }\end{array}$ & $\begin{array}{c}\text { Safety management } \\
\text { program }\end{array}$ & $\begin{array}{l}\text { 1. Testing existing safety program } \\
\text { in different organizations and } \\
\text { country contexts; } 2 \text {. Incorporating } \\
\text { intelligence and smart properties in } \\
\text { safety management programs }\end{array}$ \\
\hline
\end{tabular}

1. Safety equipment; 2. Safety training; 3. ICT in design for safety

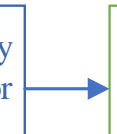

$\mathrm{H}$

Hazard recognition and risk assessment
1. ICT integrating managers' safety monitoring and workers' own safety awareness; 2 Readiness of site employees in adopting ICT

524 Fig.8. Research framework linking existing studies areas in construction safety to future directions 
assessments. A few directions in the future study of construction safety domain can be foreseen, including:

1. Updated safety climate indicator systems and safety culture models that are either crosscultural, inter-organizational, or incorporating different levels of project complexity or site conditions;

2. Integration of artificial intelligence, data analytics, and multiple ICT tools (e.g., BIM and VR) in safety planning, site monitoring, and decision making;

3. Interdisciplinary approach addressing workers health and safety especially unpleasant physical condition(Yi and Wang, 2017);

4. Tests of cognition models of workers' safety perception and behaviors incorporating their subgroup or demographic factors;

5. Smart construction site safety management enabling an effective coordination and communication between workers of different trades and management personnel;

6. User-friendly and site-ready risk management tools applying ICT.

Besides these above-mentioned emerging research directions in construction safety research, safety compliance and rule-checking could be studied in a different context such as off-site construction which is an emerging alternative construction technique that shortening the in-site construction period (Jin et al., 2018).

\section{Conclusions}

This study adopted a science mapping approach consisting of bibliometric search and scientometric analysis followed by an in-depth qualitative discussion to review over 500 journal articles in the domain of construction safety. It was found that over the past decade, there had been significant increasing publications in construction safety, especially since 2012.

554 It could be further indicated that construction safety is a traditional and everlasting research domain that is being kept updated with new elements (e.g., IT, BIM, VR). Journals that have 

analysis revealed the mainstream topics within this domain, including accident prevention, human factors, risk assessment, safety climate, safety behaviour, BIM and information technology, and hazard identification. By further dividing the literature sample into two subsamples according to their year of publications, it was found that studies within the recent decade had paid more attention on applying digital information technologies especially BIM in safety management. Other relevant topics had also become popular, including virtual reality, ontology, data mining, and analytic hierarchy process. Several keywords have a longer history but remain ongoing research themes, including human factors (e.g., safety behaviour), safety performance, safety climate, training and safety program, risk assessment, and perceptions. The scientometric analysis provided insights for the future research directions, such as applying digital information technologies and data analytics in safety management, as well as further studying how BIM affects design for safety, site monitoring, workers’ safety behaviour, and ultimately the safety performance.

Applying the same quantitative measurements (e.g., normalized citation), the influence of journals, keywords, scholars, and articles were clustered and analysed, and it is found that simulation and fall from height were the top keywords that received the highest normalized citation, indicating that the academic community had paid more attention on applying simulation techniques in safety planning, as well as commonly encountered hazards such as fall. Leading indicator is another influential keyword, meaning that proactive measurement such as safety climate is an ongoing highly studied topic. It is also found that most productive scholars in construction safety were identified according to the selected literature sample, including Hallowell, M., Gambatese, J., Li, H., Goh, Y.M., and Chan, A.P.C. Other than that

580 Zhang, S, although not with the highest number of publication, was found with highest 
581 influence in construction safety by applying BIM in safety management; In addition, the most 582 influential articles in construction safety were found related to BIM or other information 583 technologies (e.g., real-time data capturing), although traditional topics within construction 584 safety such as safety program and safety behaviour remained popular in the academic 585 community.

586 1. The in-depth qualitative discussion revealed that future research directions could be in the 587 following six areas: an adaptable safety climate and safety culture model by incorporating 588 contexts in different sites, project complexity levels, or countries;

589 2. extending established prototypes of applying information technologies to a wider $590 \quad$ construction community through more tests and case studies;

591 3. continuing studies of subgroups factors linked to cognitive models of workers' safety perception and behaviour;

4. incorporating artificial intelligence and smart properties into safety program management;

5. developing and applying information technologies that could enhance the safety communication and coordination between management personnel and workers;

6. evaluating the user acceptance and industry readiness of applying various information technologies in construction safety management.

These proposed directions for future work could benefit both academic community and industry practitioners in enhancing safety performance and improving site employees’ health

600 and wellbeing. It should be pointed out that the current review is limited to the selected 601 literature sample published in Scopus and only English journal articles were included. It might 602 have potentially excluded some latest studies published in other languages or other types of 603 documents such as trade magazines. 
605

606

607

608

609

610

611

612

613

614

615

616

617

618

619

620

621

622

623

624

625

626

627

628

629

630

631

632

633

634

635

636

637

638

639

640

641

642

643

644

645

646

647

648

649

650

651

652

653

Abudayyeh, O., Fredericks, T.K., Butt, S.E., Shaar, A., 2006. An investigation of management's commitment to construction safety. International Journal of Project Management 24, 167-174.

Aghaei Chadegani, A., Salehi, H., Md Yunus, M.M., Farhadi, H., Fooladi, M., Farhadi, M., Ale Ebrahim, N., 2013. A comparison between two main academic literature collections: Web of science and scopus databases. Asian Social Science 9, 18-26.

Aguilar, G.E., Hewage, K.N., 2013. IT based system for construction safety management and monitoring: C-RTICS2. Automation in Construction 35, 217-228.

Ai Lin Teo, E., Yean Yng Ling, F., 2006. Developing a model to measure the effectiveness of safety management systems of construction sites. Building and Environment 41, 1584-1592.

Aksan, N., Sager, L., Hacker, S., Lester, B., Dawson, J., Rizzo, M., Ebe, K., Foley, J., 2017. Individual differences in cognitive functioning predict effectiveness of a heads-up lane departure warning for younger and older drivers. Accident Analysis and Prevention 99, 171183.

Aksorn, T., Hadikusumo, B.H.W., 2008. Critical success factors influencing safety program performance in Thai construction projects. Safety Science 46, 709-727.

Al-Kaabi, N., Hadipriono, F.C., 2003. Construction safety performance in the United Arab Emirates. Civil Engineering and Environmental Systems 20, 197-212.

Ale, B.J.M., Bellamy, L.J., Baksteen, H., Damen, M., Goossens, L.H.J., Hale, A.R., Mud, M., Oh, J., Papazoglou, I.A., Whiston, J.Y., 2008. Accidents in the construction industry in the Netherlands: An analysis of accident reports using Storybuilder. Reliability Engineering and System Safety 93, 1523-1533.

Alruqi, W.M., Hallowell, M.R., Techera, U., 2018. Safety climate dimensions and their relationship to construction safety performance: A meta-analytic review. Safety Science 109, 165-173.

Ardeshir, A., Mohajeri, M., 2018. Assessment of safety culture among job positions in highrise construction: a hybrid fuzzy multi criteria decision-making (FMCDM) approach. International Journal of Injury Control and Safety Promotion 25, 195-206.

Ardeshir, A., Mohajeri, M., Amiri, M., 2016. Evaluation of safety risks in construction using Fuzzy Failure Mode and Effect Analysis (FFMEA). Scientia Iranica 23, 2546-2556.

Bavafa, A., Mahdiyar, A., Marsono, A.K., 2018. Identifying and assessing the critical factors for effective implementation of safety programs in construction projects. Safety Science 106, 47-56.

Behm, M., 2005. Linking construction fatalities to the design for construction safety concept. Safety Science 43, 589-611.

Bigelow, P.L., Gilkey, D.P., Greenstein, S., Kirsch, M.P., 1998. Evaluation of HomeSafe: An injury and illness prevention program in residential construction. Work 11, 21-33.

Butler, L., Visser, M.S., 2006. Extending citation analysis to non-source items. Scientometrics 66, 327-343.

Carter, G., Smith, S.D., 2006. Safety hazard identification on construction projects. Journal of Construction Engineering and Management 132, 197-205.

Chan, A.P.C., Javed, A.A., Wong, F.K.W., Hon, C.K.H., Lyu, S., 2017. Evaluating the Safety Climate of Ethnic Minority Construction Workers in Hong Kong. Journal of Professional Issues in Engineering Education and Practice 143.

Chen, F., Liu, Y., 2015. Innovation performance study on the construction safety of urban subway engineering based on Bayesian network: A case study of BIM innovation project. Journal of Applied Science and Engineering 18, 233-244.

Chen, Q., Jin, R., 2012. Safety4Site commitment to enhance jobsite safety management and performance. Journal of Construction Engineering and Management 138, 509-519. 
Chen, Q., Jin, R., 2013. Multilevel safety culture and climate survey for assessing new safety Program. Journal of Construction Engineering and Management 139, 805-817.

Chen, Q., Jin, R., 2015. A comparison of subgroup construction workers' perceptions of a safety program. Safety Science 74, 15-26.

Chen, Q., Jin, R., Soboyejo, A., 2013. Understanding a contractor's regional variations in safety performance. Journal of Construction Engineering and Management 139, 641-653.

Chen, Y., McCabe, B., Hyatt, D., 2018. A resilience safety climate model predicting construction safety performance. Safety Science 109, 434-445.

Cheng, T., Teizer, J., 2013. Real-time resource location data collection and visualization technology for construction safety and activity monitoring applications. Automation in Construction 34, 3-15.

Cheung, E., Chan, A.P.C., 2012. Rapid demountable platform (RDP) - A device for preventing fall from height accidents. Accident Analysis and Prevention 48, 235-245.

Cheung, W.F., Lin, T.H., Lin, Y.C., 2018. A real-time construction safety monitoring system for hazardous gas integrating wireless sensor network and building information modeling technologies. Sensors (Switzerland) 18.

Choe, S., Leite, F., 2017. Construction safety planning: Site-specific temporal and spatial information integration. Automation in Construction 84, 335-344.

Choe, S., Leite, F., Seedah, D., Caldas, C., 2014. Evaluation of sensing technology for the prevention of backover accidents in construction work zones. Journal of Information Technology in Construction 19, 1-19.

Choi, B., Ahn, S., Lee, S., 2017. Construction Workers' Group Norms and Personal Standards Regarding Safety Behavior: Social Identity Theory Perspective. Journal of Management in Engineering 33.

Choudhry, R.M., Fang, D., 2008. Why operatives engage in unsafe work behavior: Investigating factors on construction sites. Safety Science 46, 566-584.

Choudhry, R.M., Fang, D., Mohamed, S., 2007. The nature of safety culture: A survey of the state-of-the-art. Safety Science 45, 993-1012.

Choudhry, R.M., Fang, D., Mohamed, S., 2009. Closure to "developing a model of construction safety culture" by Rafiq M. Choudhry, Dongping Fang, and Sherif Mohamed. Journal of Management in Engineering 25, 45-47.

Enshassi, A.A., Mayer, P.E., Choudhry, R.M., Hassouna, A.M., 2007. Perception of contracing parties on construction safety in the Gaza Strip, Palestine. Arab Gulf Journal of Scientific Research 25, 120-129.

Fang, D., Zhao, C., Zhang, M., 2016. A cognitive model of construction workers' unsafe behaviors. Journal of Construction Engineering and Management 142.

Gambatese, J.A., Behm, M., Hinze, J.W., 2005. Viability of designing for construction worker safety. Journal of Construction Engineering and Management 131, 1029-1036.

Gambatese, J.A., Behm, M., Rajendran, S., 2008. Design's role in construction accident causality and prevention: Perspectives from an expert panel. Safety Science 46, 675-691.

Gambatese, J.A., Hinze, J.W., Haas, C.T., 1997. Tool to design for construction worker safety. Journal of Architectural Engineering 3, 32-41.

Gao, R., Chan, A.P.C., Lyu, S., Zahoor, H., Utama, W.P., 2018. Investigating the difficulties of implementing safety practices in international construction projects. Safety Science 108, 39-47.

Gao, R., Chan, A.P.C., Utama, W.P., Zahoor, H., 2016. Multilevel safety climate and safety performance in the construction industry: Development and validation of a top-down mechanism. International Journal of Environmental Research and Public Health 13. 
Garrett, J.W., Teizer, J., 2009. Human factors analysis classification system relating to human error awareness taxonomy in construction safety. Journal of Construction Engineering and Management 135, 754-763.

Gibb, A., Lingard, H., Behm, M., Cooke, T., 2014. Construction accident causality: Learning from different countries and differing consequences. Construction Management and Economics 32, 446-459.

Goh, Y.M., Askar Ali, M.J., 2016. A hybrid simulation approach for integrating safety behavior into construction planning: An earthmoving case study. Accident Analysis and Prevention 93, 310-318.

Goh, Y.M., Ubeynarayana, C.U., 2017. Construction accident narrative classification: An evaluation of text mining techniques. Accident Analysis and Prevention 108, 122-130.

Goncalves Filho, A.P., Waterson, P., 2018. Maturity models and safety culture: A critical review. Safety Science 105, 192-211.

Guldenmund, F.W., 2000. The nature of safety culture: A review of theory and research. Safety Science 34, 215-257.

Guo, B.H.W., Goh, Y.M., 2017. Ontology for design of active fall protection systems. Automation in Construction 82, 138-153.

Guo, B.H.W., Goh, Y.M., Le Xin Wong, K., 2018a. A system dynamics view of a behaviorbased safety program in the construction industry. Safety Science 104, 202-215.

Guo, B.H.W., Yiu, T.W., González, V.A., 2018b. Does company size matter? Validation of an integrative model of safety behavior across small and large construction companies. Journal of Safety Research 64, 73-81.

Guo, B.H.W., Yiu, T.W., González, V.A., Goh, Y.M., 2017a. Using a Pressure-State-Practice Model to Develop Safety Leading Indicators for Construction Projects. Journal of Construction Engineering and Management 143.

Guo, H., Yu, Y., Ding, Q., Skitmore, M., 2018c. Image-and-Skeleton-Based Parameterized Approach to Real-Time Identification of Construction Workers' Unsafe Behaviors. Journal of Construction Engineering and Management 144.

Guo, H., Yu, Y., Xiang, T., Li, H., Zhang, D., 2017b. The availability of wearable-devicebased physical data for the measurement of construction workers' psychological status on site: From the perspective of safety management. Automation in Construction 82, 207-217.

Gürcanli, G.E., Müngen, U., 2009. An occupational safety risk analysis method at construction sites using fuzzy sets. International Journal of Industrial Ergonomics 39, 371-387.

Hallowell, M.R., Gambatese, J.A., 2009. Construction safety risk mitigation. Journal of Construction Engineering and Management 135, 1316-1323.

Han, Y., Feng, Z., Zhang, J., Jin, R., Aboagye-Nimo, E., 2018. An Empirical Study of Employees' Safety Perceptions of Site Hazard/Accident Scenes. Journal of Construction Engineering and Management in Press, DOI: 10.1061/(ASCE)CO.1943-7862.0001590.

Haslam, R.A., Hide, S.A., Gibb, A.G.F., Gyi, D.E., Pavitt, T., Atkinson, S., Duff, A.R., 2005. Contributing factors in construction accidents. Applied Ergonomics 36, 401-415.

He, Q., Wang, G., Luo, L., Shi, Q., Xie, J., Meng, X., 2017. Mapping the managerial areas of Building Information Modeling (BIM) using scientometric analysis. International Journal of Project Management 35, 670-685.

Hinze, J., Thurman, S., Wehle, A., 2013. Leading indicators of construction safety performance. Safety Science 51, 23-28.

Hosseini, M.R., Martek, I., Zavadskas, E.K., Aibinu, A.A., Arashpour, M., Chileshe, N., 2018. Critical evaluation of off-site construction research: A Scientometric analysis. Automation in Construction 87, 235-247. 
Hsueh, S.L., Huang, C.F., Tseng, C.Y., 2013. Using data mining technology to explore labor safety strategy- A lesson from the construction industry. Pakistan Journal of Statistics 29, 611-620.

Huang, G., Sun, S., Zhang, D., 2018. Safety Evaluation of Construction Based on the Improved AHP-Grey Model. Wireless Personal Communications, 1-11.

Huang, X., Hinze, J., 2006. Owner's role in construction safety. Journal of Construction Engineering and Management 132, 164-173.

Jaselskis, E.J., Anderson, S.D., Russell, J.S., 1996. Strategies for achieving excellence in construction safety performance. Journal of Construction Engineering and Management 122, 61-70.

Jeelani, I., Han, K., Albert, A., 2018. Automating and scaling personalized safety training using eye-tracking data. Automation in Construction 93, 63-77.

Jeschke, K.C., Kines, P., Rasmussen, L., Andersen, L.P.S., Dyreborg, J., Ajslev, J., Kabel, A., Jensen, E., Andersen, L.L., 2017. Process evaluation of a Toolbox-training program for construction foremen in Denmark. Safety Science 94, 152-160.

Jiang, H., Wang, J., Han, Y., Yin, H., 2018. Structural equation model analysis of factors in the spread of unsafe behavior among constructionworkers. Information (Switzerland) 9.

Jin, R., Gao, S., Cheshmehzangi, A., Aboagye-Nimo, E., 2018. A Holistic Review of off-site Construction Literature Published between 2008 and 2018. Journal of Cleaner Production 202, 1202-1219.

Ju, C., Rowlinson, S., 2014. Institutional determinants of construction safety management strategies of contractors in Hong Kong. Construction Management and Economics 32, 725736.

Karakhan, A.A., Rajendran, S., Gambatese, J., Nnaji, C., 2018. Measuring and Evaluating Safety Maturity of Construction Contractors: Multicriteria Decision-Making Approach. Journal of Construction Engineering and Management 144.

Kartam, N.A., 1997. Integrating safety and health performance into construction CPM. Journal of Construction Engineering and Management 123, 121-126.

Kim, S., Shin, D.H., Woo, S., Lee, S., 2014. Identification of IT application areas and potential solutions for perception enhancement to improve construction safety. KSCE Journal of Civil Engineering 18, 365-379.

Kim, S.H., Ryu, H.G., Kang, C.S., 2019. Development of an iot-based construction site safety management system, In: Kim, K.J., Kim, K.J., Baek, N. (Eds.), International Conference on Information Science and Applications, ICISA 2018. Springer Verlag, pp. 617-624.

Koch, C., 2013. From crew to country? Local and national construction safety cultures in Denmark. Construction Management and Economics 31, 691-703.

Le, Q.T., Pedro, A., Park, C.S., 2015. A Social Virtual Reality Based Construction Safety Education System for Experiential Learning. Journal of Intelligent and Robotic Systems: Theory and Applications 79, 487-506.

Lee, H.S., Lee, K.P., Park, M., Baek, Y., Lee, S., 2012. RFID-based real-time locating system for construction safety management. Journal of Computing in Civil Engineering 26, 366377.

Lette, A., Ambelu, A., Getahun, T., Mekonen, S., 2018. A survey of work-related injuries among building construction workers in southwestern Ethiopia. International Journal of Industrial Ergonomics 68, 57-64.

Li, H., Chan, G., Huang, T., Skitmore, M., Tao, T.Y.E., Luo, E., Chung, J., Chan, X.S., Li, Y.F., 2015a. Chirp-spread-spectrum-based real time location system for construction safety management: A case study. Automation in Construction 55, 58-65.

Li, H., Lu, M., Chan, G., Skitmore, M., 2015b. Proactive training system for safe and efficient precast installation. Automation in Construction 49, 163-174. 
Li, H., Lu, M., Hsu, S.C., Gray, M., Huang, T., 2015c. Proactive behavior-based safety management for construction safety improvement. Safety Science 75, 107-117.

Li, Q., Ji, C., Yuan, J., Han, R., 2017. Developing dimensions and key indicators for the safety climate within China's construction teams: A questionnaire survey on construction sites in Nanjing. Safety Science 93, 266-276.

Li, X., Yi, W., Chi, H.L., Wang, X., Chan, A.P.C., 2018a. A critical review of virtual and augmented reality (VR/AR) applications in construction safety. Automation in Construction 86, 150-162.

Li, Y., Hu, Y., Xia, B., Skitmore, M., Li, H., 2018b. Proactive behavior-based system for controlling safety risks in urban highway construction megaprojects. Automation in Construction 95, 118-128.

Liao, P.C., Shi, H., Su, Y., Luo, X., 2018. Development of Data-Driven Influence Model to Relate the Workplace Environment to Human Error. Journal of Construction Engineering and Management 144.

Lingard, H., Rowlinson, S., 2015. Occupational Health and safety in construction management. Spon Press, Oxon, UK.

Liu, J., 2018. Study on the safety cognition deviation characteristics and formation mechanism of construction workers. Master Thesis. Jiangsu University, Zhenjiang, Jiangsu, China, 1216.

Liu, J., Gong, E., Wang, D., Teng, Y., 2018. Cloud Model-Based Safety Performance Evaluation of Prefabricated Building Project in China. Wireless Personal Communications, 1-19.

Liu, K.T., Lee, Y.L., Shiau, Y.C., Lin, C.C., 2017. Examining the layout of scaffolds and decks used in construction projects from the perspective of building information modelling. ICIC Express Letters, Part B: Applications 8, 319-326.

Lu, Y., Li, Q., Zhou, Z., Deng, Y., 2015. Ontology-based knowledge modeling for automated construction safety checking. Safety Science 79, 11-18.

Lyu, N., Xie, L., Wu, C., Fu, Q., Deng, C., 2017. Driver’s cognitive workload and driving performance under traffic sign information exposure in complex environments: A case study of the highways in China. International Journal of Environmental Research and Public Health 14.

Lyu, S., Hon, C.K.H., Chan, A.P.C., Wong, F.K.W., Javed, A.A., 2018. Relationships among safety climate, safety behavior, and safety outcomes for ethnic minority construction workers. International Journal of Environmental Research and Public Health 15.

Malekitabar, H., Ardeshir, A., Sebt, M.H., Stouffs, R., 2016. Construction safety risk drivers: A BIM approach. Safety Science 82, 445-455.

Manu, P., Ankrah, N., Proverbs, D., Suresh, S., 2010. An approach for determining the extent of contribution of construction project features to accident causation. Safety Science 48, 687-692.

Marquardt, N., Gades, R., Robelski, S., 2012. Implicit social cognition and safety culture. Human Factors and Ergonomics In Manufacturing 22, 213-234.

Martínez-Aires, M.D., López-Alonso, M., Martínez-Rojas, M., 2018. Building information modeling and safety management: A systematic review. Safety Science 101, 11-18.

McCabe, B.Y., Alderman, E., Chen, Y., Hyatt, D.E., Shahi, A., 2017. Safety Performance in the Construction Industry: Quasi-Longitudinal Study. Journal of Construction Engineering and Management 143.

Melzner, J., Zhang, S., Teizer, J., Bargstädt, H.J., 2013. A case study on automated safety compliance checking to assist fall protection design and planning in building information models. Construction Management and Economics 31, 661-674. 
862

863

864

865

866

867

868

869

870

871

872

873

874

875

876

877

878

879

880

881

882

883

884

885

886

887

888

889

890

891

892

893

894

895

896

Mohamed, S., 1999. Empirical investigation of construction safety management activities and performance in Australia. Safety Science 33, 129-142.

Mohammadi, A., Tavakolan, M., Khosravi, Y., 2018. Factors influencing safety performance on construction projects: A review. Safety Science 109, 382-397.

Newaz, M.T., Davis, P.R., Jefferies, M., Pillay, M., 2018. Developing a safety climate factor model in construction research and practice: A systematic review identifying future directions for research. Engineering, Construction and Architectural Management 25, 738757.

Ning, X., Qi, J., Wu, C., 2018. A quantitative safety risk assessment model for construction site layout planning. Safety Science 104, 246-259.

Niu, Y., Lu, W., Xue, F., Liu, D., Chen, K., Fang, D., Anumba, C., 2018. Towards the "third wave": An SCO-enabled occupational health and safety management system for construction. Safety Science.

OSHA, 2011. “Construction Focus Four training.” U.S. Dept. of Labor, Washington, DC,〈http://www.osha.gov/dte/outreach/construction/focus_four/index.html) (Apr. 13, 2017).

Oswald, D., Sherratt, F., Smith, S.D., Hallowell, M.R., 2018. Exploring safety management challenges for multi-national construction workforces: a UK case study. Construction Management and Economics 36, 291-301.

Park, C.S., Kim, H.J., 2013. A framework for construction safety management and visualization system. Automation in Construction 33, 95-103.

Park, J., Kim, K., Cho, Y.K., 2017. Framework of Automated Construction-Safety Monitoring Using Cloud-Enabled BIM and BLE Mobile Tracking Sensors. Journal of Construction Engineering and Management 143.

Park, J., Marks, E., Cho, Y.K., Suryanto, W., 2016. Performance test of wireless technologies for personnel and equipment proximity sensing in work zones. Journal of Construction Engineering and Management 142.

Pedro, A., Le, Q.T., Park, C.S., 2016. Framework for Integrating Safety into Construction Methods Education through Interactive Virtual Reality. Journal of Professional Issues in Engineering Education and Practice 142.

Peng, J., 2017. Corrosion detection of reinforcement of building materials with piezoelectric sensors. Kemija u industriji/Journal of Chemists and Chemical Engineers 66, 261-265.

Pereira, E., Ahn, S., Han, S., Abourizk, S., 2018. Identification and Association of HighPriority Safety Management System Factors and Accident Precursors for Proactive Safety Assessment and Control. Journal of Management in Engineering 34.

Perlman, A., Sacks, R., Barak, R., 2014. Hazard recognition and risk perception in construction. Safety Science 64, 13-21.

Pinto, A., Nunes, I.L., Ribeiro, R.A., 2011. Occupational risk assessment in construction industry - Overview and reflection. Safety Science 49, 616-624.

Priemus, H., Ale, B., 2010. Construction safety: An analysis of systems failure. The case of the multifunctional Bos \& Lommerplein estate, Amsterdam. Safety Science 48, 111-122.

Qi, J., Issa, R.R.A., Olbina, S., Hinze, J., 2014. Use of building information modeling in design to prevent construction worker falls. Journal of Computing in Civil Engineering 28.

Rivas, T., Paz, M., Martín, J.E., Matías, J.M., García, J.F., Taboada, J., 2011. Explaining and predicting workplace accidents using data-mining techniques. Reliability Engineering and System Safety 96, 739-747.

Sacks, R., Perlman, A., Barak, R., 2013. Construction safety training using immersive virtual reality. Construction Management and Economics 31, 1005-1017. 
Sacks, R., Whyte, J., Swissa, D., Raviv, G., Zhou, W., Shapira, A., 2015. Safety by design: dialogues between designers and builders using virtual reality. Construction Management and Economics 33, 55-72.

Salas, R., Hallowell, M., 2016. Predictive Validity of Safety Leading Indicators: Empirical Assessment in the Oil and Gas Sector. Journal of Construction Engineering and Management 142.

Sandberg, E., Albrechtsen, E., 2018. A study of experience feedback from reported unwanted occurrences in a construction company. Safety Science 107, 46-54.

Shahbodaghlou, F., Haven, R., 2000. A model for a quality safety program. Journal of Construction Education 5, 260-271.

Shen, X., Marks, E., 2016. Near-Miss Information Visualization Tool in BIM for Construction Safety. Journal of Construction Engineering and Management 142.

Song, J., Zhang, H., Dong, W., 2016. A review of emerging trends in global PPP research: analysis and visualization. Scientometrics 107, 1111-1147.

Song, Z., Liu, Q., Hu, Z., Li, H., Xiong, J., 2018. Assessment of sediment impact on the risk of river diversion during dam construction: A simulation-based project study on the Jing River, China. Water (Switzerland) 10.

Stiehl, E., Forst, L., 2018. Safety climate among nontraditionalworkers in construction: Arguing for a focus on construed external safety image. New Solutions 28, 33-54.

Strahan, C., Watson, B., Lennonb, A., 2008. Can organisational safety climate and occupational stress predict work-related driver fatigue? Transportation Research Part F: Traffic Psychology and Behaviour 11, 418-426.

Su, H.N., Lee, P.C., 2010. Mapping knowledge structure by keyword co-occurrence: A first look at journal papers in Technology Foresight. Scientometrics 85, 65-79.

Sunindijo, R.Y., Zou, P.X.W., 2012. Political skill for developing construction safety climate. Journal of Construction Engineering and Management 138, 605-612.

Suo, Q., Zhang, D., 2017. Investigation and identification of factors affecting migrating peasant workers' usage of safety footwear in the Chinese construction industry. International Journal of Occupational Safety and Ergonomics 23, 424-430.

Swuste, P., Frijters, A., Guldenmund, F., 2012. Is it possible to influence safety in the building sector?. A literature review extending from 1980 until the present. Safety Science 50, 13331343.

Tam, C.M., Tong, T.K.L., Chiu, G.C.W., Fung, I.W.H., 2002. Non-structural fuzzy decision support system for evaluation of construction safety management system. International Journal of Project Management 20, 303-313.

Tam, C.M., Zeng, S.X., Deng, Z.M., 2004. Identifying elements of poor construction safety management in China. Safety Science 42, 569-586.

Teizer, J., Allread, B.S., Fullerton, C.E., Hinze, J., 2010. Autonomous pro-active real-time construction worker and equipment operator proximity safety alert system. Automation in Construction 19, 630-640.

Teo, A.L.E., Ofori, G., Tjandra, I.K., Kim, H., 2016. Design for safety: Theoretical framework of the safety aspect of BIM system to determine the safety index. Construction Economics and Building 16, 1-18.

Teo, E.A.L., Feng, Y., 2009. The role of safety climate in predicting safety culture on construction sites. Architectural Science Review 52, 5-16.

Tixier, A.J.P., Hallowell, M.R., Rajagopalan, B., Bowman, D., 2016. Automated content analysis for construction safety: A natural language processing system to extract precursors and outcomes from unstructured injury reports. Automation in Construction 62, 45-56. 
Trinh, M.T., Feng, Y., Jin, X., 2018. Conceptual Model for Developing Resilient Safety Culture in the Construction Environment. Journal of Construction Engineering and Management 144.

U.S. Bureau of Labor Statistics, 2016. "Employer-reported workplace injuries and illnesses 2015.”<https://www.bls.gov/iif/oshsum.htm\#16Summary_Tables> (May 14th, 2018).

van Eck, N.J., Waltman, L., 2010. Software survey: VOSviewer, a computer program for bibliometric mapping. Scientometrics 84, 523-538.

Van Eck, N.J., Waltman, L., 2014. Visualizing bibliometric networks. . In Y. Ding, R. Rousseau, \& D. Wolfram (Eds.), Measuring scholarly impact: Methods and practice, 285320).

van Eck, N.J., Waltman, L., 2017. VOSviewer Manual. Manual for VOSviewer version 1.6.6. Wang, J., Zhang, S., Teizer, J., 2015. Geotechnical and safety protective equipment planning using range point cloud data and rule checking in building information modeling. Automation in Construction 49, 250-261.

Wasilkiewicz, K., Albrechtsen, E., Antonsen, S., 2016. Occupational safety in a globalized construction industry: A study on Polish workers in Norway. Policy and Practice in Health and Safety 14, 128-143.

Wen Lim, H., Li, N., Fang, D., Wu, C., 2018. Impact of Safety Climate on Types of Safety Motivation and Performance: Multigroup Invariance Analysis. Journal of Management in Engineering 34.

Winge, S., Albrechtsen, E., 2018. Accident types and barrier failures in the construction industry. Safety Science 105, 158-166.

Winge, S., Albrechtsen, E., Mostue, B.A., 2019. Causal factors and connections in construction accidents. Safety Science 112, 130-141.

Wong, F.K.W., Chan, A.P.C., Yam, M.C.H., Wong, E.Y.S., Tse, K.T.C., Yip, K.K.C., Cheung, E., 2009. Findings from a research study of construction safety in Hong Kong: Accidents related to fall of person from height. Journal of Engineering, Design and Technology 7, 130142.

Wu, C., Fang, D., Li, N., 2015a. Roles of owners' leadership in construction safety: The case of high-speed railway construction projects in China. International Journal of Project Management 33, 1665-1679.

Wu, C., Song, X., Wang, T., Fang, D., 2015b. Core Dimensions of the Construction Safety Climate for a Standardized Safety-Climate Measurement. Journal of Construction Engineering and Management 141.

Wu, C., Wang, F., Zou, P.X.W., Fang, D., 2016. How safety leadership works among owners, contractors and subcontractors in construction projects. International Journal of Project Management 34, 789-805.

Xia, N., Griffin, M.A., Wang, X., Liu, X., Wang, D., 2018. Is there agreement between worker self and supervisor assessment of worker safety performance? An examination in the construction industry. Journal of Safety Research 65, 29-37.

Yi, S.L., Zhang, X., Calvo, M.H., 2015. Construction safety management of building project based on BIM. Journal of Mechanical Engineering Research and Developments 38, 97-104.

Yi, W., Chan, A.P.C., 2017. Effects of heat stress on construction labor productivity in Hong Kong: A case study of rebar workers. International Journal of Environmental Research and Public Health 14.

Yi, W., Wang, S., 2017. Mixed-Integer Linear Programming on Work-Rest Schedule Design for Construction Sites in Hot Weather. Computer-Aided Civil and Infrastructure Engineering 32, 429-439. 
Yiu, N.S.N., Sze, N.N., Chan, D.W.M., 2018. Implementation of safety management systems in Hong Kong construction industry - A safety practitioner's perspective. Journal of Safety Research 64, 1-9.

Zahoor, H., Chan, A.P.C., Utama, W.P., Gao, R., Memon, S.A., 2017. Determinants of Safety Climate for Building Projects: SEM-Based Cross-Validation Study. Journal of Construction Engineering and Management 143.

Zhang, L., Chen, H., Li, H., Wu, X., Skibniewski, M.J., 2018a. Perceiving interactions and dynamics of safety leadership in construction projects. Safety Science 106, 66-78.

Zhang, L., Kang, J., Luo, H., Zhong, B., 2018b. Drivers’ physiological response and emotional evaluation in the noisy environment of the control cabin of a shield tunneling machine. Applied Acoustics 138, 1-8.

Zhang, P., Li, N., Fang, D., Wu, H., 2017. Supervisor-focused behavior-based safety method for the construction industry: Case study in Hong Kong. Journal of Construction Engineering and Management 143.

Zhang, S., Boukamp, F., Teizer, J., 2015a. Ontology-based semantic modeling of construction safety knowledge: Towards automated safety planning for job hazard analysis (JHA). Automation in Construction 52, 29-41.

Zhang, S., Sulankivi, K., Kiviniemi, M., Romo, I., Eastman, C.M., Teizer, J., 2015b. BIMbased fall hazard identification and prevention in construction safety planning. Safety Science 72, 31-45.

Zhang, S., Teizer, J., Lee, J.K., Eastman, C.M., Venugopal, M., 2013. Building Information Modeling (BIM) and Safety: Automatic Safety Checking of Construction Models and Schedules. Automation in Construction 29, 183-195.

Zhao, X., 2017. A scientometric review of global BIM research: Analysis and visualization. Automation in Construction 80, 37-47.

Zhou, Z., Irizarry, J., Li, Q., 2013. Applying advanced technology to improve safety management in the construction industry: a literature review. Construction Management and Economics 31, 606-622.

Zou, P.X.W., Lun, P., Cipolla, D., Mohamed, S., 2017a. Cloud-based safety information and communication system in infrastructure construction. Safety Science 98, 50-59.

Zou, Y., Kiviniemi, A., Jones, S.W., 2017b. A review of risk management through BIM and BIM-related technologies. Safety Science 97, 88-98. 